\title{
Cx43 Hemichannels and Gap Junction Channels in Astrocytes Are Regulated Oppositely by Proinflammatory Cytokines Released from Activated Microglia
}

\author{
Mauricio A. Retamal, ${ }^{1}$ Nicolas Froger,, 23 Nicolas Palacios-Prado, ${ }^{1}$ Pascal Ezan, ${ }^{2,3}$ Pablo J. Sáez, ${ }^{1}$ Juan C. Sáez, ${ }^{1}$ and \\ Christian Giaume ${ }^{2,3}$ \\ ${ }^{1}$ Departamento de Ciencias Fisiológicas, Pontificia Universidad Católica de Chile, Santiago 6513492, Chile, ${ }^{2}$ Institut National de la Santé et de la Recherche \\ Médicale, U840, 75005 Paris, France, and ${ }^{3}$ Collège de France, 75005 Paris, France
}

\begin{abstract}
Astrocytes have a role in maintaining normal neuronal functions, some of which depend on connexins, protein subunits of gap junction channels and hemichannels. Under inflammatory conditions, microglia release cytokines, including interleukin- $1 \beta$ and tumor necrosis factor- $\alpha$, that reduce intercellular communication via gap junctions. Now, we demonstrate that either conditioned medium harvested from activated microglia or a mixture of these two cytokines enhances the cellular exchange with the extracellular milieu via Cx43 hemichannels. These changes in membrane permeability were not detected in astrocytes cultured from Cx43 knock-out mice and were abrogated by connexin hemichannel blockers, including $\mathrm{La}^{3+}$, mimetic peptides, and niflumic acid. Both the reduction in gap junctional communication and the increase in membrane permeability were mediated by a p38 mitogen-activated protein kinase-dependent pathway. However, the increase in membrane permeability, but not the gap junction inhibition, was rapidly reversed by the sulfhydryl reducing agent dithiothreitol, indicating that final regulatory mechanisms are different. Treatment with proinflammatory cytokines reduced the total and cell surface $\mathrm{Cx} 43$ levels, suggesting that the increase in membrane permeability was attributable to an increase in hemichannels activity. Indeed, unitary events of $\sim 220 \mathrm{pS}$ corresponding to $\mathrm{Cx} 43$ hemichannels were much more frequent in astrocytes treated with microglia conditioned medium than under control conditions. Finally, the effect of cytokines enhanced the uptake and reduced the intercellular diffusion of glucose, which might explain changes in the metabolic status of astrocytes under inflammatory conditions. Accordingly, this opposite regulation may affect glucose trafficking and certainly will modify the metabolic status of astrocytes involved in brain inflammation.
\end{abstract}

Key words: glial cells; connexin; inflammation; nitric oxide; gap junction; glucose

\section{Introduction}

Brain inflammation is a widespread process associated with neurodegenerative diseases. This pathophysiological response is characterized by astrocyte reactivity (Little and O'Callagha, 2001; Sofroniew, 2005) and microglia (MG) activation (Eugenín et al., 2003), resulting in production of proinflammatory cytokines, mainly from activated MG (Minami et al., 2006). Under normal conditions, cultured astrocytes are highly coupled through gap junction channels composed of connexin43 (Cx43) (Giaume et al., 1991). The inhibition of astrocytic gap junctional communication (GJC), proceeded by the addition of resting MG on cul-

\footnotetext{
Received May 4, 2007; revised Sept. 21, 2007; accepted Sept. 24, 2007.

This work was supported, in part, by Fondo Nacional de Desarrollo Científico y Tecnológico Grants 1030945 and 1070591 (J.C.S.), Núcleo Milenio P04/03-F (J.C.S.), Institut National de la Santé et de la Recherche Médicale/Consejo Nacional de Ciencia y Tecnologia (C.G., J.C.S.), and a grant from Caisse de Retraite et de Prevoyance des Clercs et Employés de Notaires (C.G.). Mauricio A. Retamal was a postdoctoral fellow of the Núcleo Milenio P04/030-F. We thank Prof. Christian C. Naus for his valuable comments.

Correspondence should be addressed to either of the following: Dr. Christian Giaume, Institut National de la Santé et de la Recherche Médicale U840, Collège de France, 11 place Marcelin Berthelot, 75005 Paris, France, E-mail: christian.giaume@college-de-france.fr; or Dr. Juan C. Sáez, Departamento de Ciencias Fisiológicas, Universidad Católica de Chile, Alameda 340, Santiago 6513492, Chile, E-mail: jsaez@bio.puc.cl.

D0I:10.1523/JNEUROSCI.2042-07.2007

Copyright $\odot 2007$ Society for Neuroscience $\quad$ 0270-6474/07/2713781-12\$15.00/0
}

tured astrocytes, has suggested a functional interaction between astrocytic GJC and MG (Rouach et al., 2002b). Recently, soluble factors secreted by activated MG were identified as responsible for the stronger inhibition of astrocyte-astrocyte GJC (Faustmann et al., 2003; Même et al., 2006). At least two proinflammatory cytokines, interleukin-1 $\beta$ (IL-1 $\beta$ ) and tumor necrosis factor- $\alpha$ (TNF- $\alpha$ ), were shown to be specifically involved in this inhibition (Même et al., 2006). Furthermore, astrocytic GJC inhibition was also described in other pathological conditions such as ischemia-reperfusion (Cotrina et al., 1998; Contreras et al., 2003).

In the last few years, a new role of Cxs was demonstrated by the evidence of $\mathrm{Cx}$ hemichannels providing a pathway for molecular exchange between the cytoplasm and the extracellular compartment (Sáez et al., 2005). Under resting in vitro conditions, these hemichannels, located at nonapposed plasma membrane domains, present a low open probability that can be increased in well-defined conditions (Sáez et al., 2005; Retamal et al., 2007). Their opening allows the release of molecules such as $\mathrm{NAD}^{+}$, ATP, glutamate, prostaglandin $\mathrm{E}_{2}$, and glutathione (Bruzzone et al., 2001; Stout et al., 2002; Ye et al., 2003; Cherian et al., 2005; Rana and Dringen, 2007), providing a paracrine route for inter- 
cellular communication. Finally, increased $\mathrm{Cx} 43$ hemichannel activity contributes to cell death in several cell types, including astrocytes (Contreras et al., 2002), renal tubules (Vergara et al., 2003) and cardiomyocytes (John et al., 1999), suggesting that they can determinate the extension of cellular damage. Although expected, thus far, there is no evidence that $\mathrm{Cx}$ hemichannels could also allow the uptake of signals or metabolic molecules that could also contribute to certain pathologies.

In the present report, we studied the effects of activated MG or their released proinflammatory cytokines on astrocytic $\mathrm{Cx} 43$ hemichannels and compared them to their gap junction channel function. We found that the addition of MG activated by lipopolysaccharide (LPS) or conditioned medium harvested from activated MG or a cytokine mixture (IL- $1 \beta$ and TNF- $\alpha$ ) increases astrocyte permeability to ethidium bromide (EthBr) through Cx43 hemichannels, a process that parallels the inhibition of GJC. These opposite regulations share a MAP kinase pathway but differ in the involvement of nitric oxide. Interestingly, a reduction of Cx43 expression level was observed, suggesting that treatment with proinflammatory agents increases the open probability of Cx43 hemichannels. This statement was confirmed by patchclamp recording of $\mathrm{Cx} 43$ hemichannel activity. Finally, using the fluorescent glucose derivative, 2-(N-(7-nitrobenz-2-oxa-1,3diazol-4-yl)amino)-deoxyglucose (2-NBDG), we demonstrated that these latter treatments reduced the intercellular diffusion of 2-NBDG while they favor its uptake.

\section{Materials and Methods Animals}

MG and astrocyte cultures were prepared from OF1 mice (Charles River, L'Arbresle, France). In addition, Cx43-deficient astrocytes were obtained from Cx43 knock-out mice, whereas $\mathrm{Cx} 43+1+$ wild-type astrocytes, cultured from mice with the same genetic background, were taken as their control (Reaume et al., 1995). Homozygous mutant (Cx43-/-) and their wild-type control $(\mathrm{Cx} 43+/+)$ mice were the product of mating between heterozygous $\mathrm{Cx} 43+/-$. $\mathrm{Cx} 43-/-$ die immediately after birth primarily because of cardiovascular disorders; consequently, newborn mice were used within a few hours after delivery. Heterozygous couples $(\mathrm{Cx} 43+/-)$, raised on 129/Sv $\times$ C57BL/6 genetic background were bred at the laboratory under standard conditions ( $12 \mathrm{~h}$ light/dark cycle; $22 \pm$ $1{ }^{\circ} \mathrm{C}$ ambient temperature; $60 \%$ relative humidity; food and water ad libitum). Genotyping was performed from a tissue sample, using PCR analysis, as described below.

All experiments were performed in accordance with the European Community Council Directives of November 24, 1986 (86/609/EEC), and all efforts were made to minimize the number of animals used and their suffering.

\section{Cultures}

Astrocyte cultures. Primary astrocyte cultures were prepared from the cortex of newborn (1-2 d of age) OF1 mice as described previously (Même et al., 2006). Briefly, cells were seeded into 100-mm-diameter plastic dishes (Nunc, Roskilde, Denmark) at the density of $3 \times 10^{6}$ cells/dish in DMEM (Sigma-Aldrich, St-Louis, MO), supplemented with penicillin $(5 \mathrm{U} / \mathrm{ml})$, streptomycin $(5 \mu \mathrm{g} / \mathrm{ml})$ (Invitrogen, Carlsbad, CA), and $10 \%$ FCS (Hyclone, Logan, UT). The medium was changed twice each week. When cells reached confluence, at $\sim 10 \mathrm{~d}$ in vitro (DIV), they were harvested with trypsin-EDTA (Invitrogen). Then, cells were replated $\left(2 \times 10^{5}\right.$ cells/well), as secondary cultures, on glass coverslips (Gassalem, Limeil-Brévannes, France) placed inside 16-mm-diameter 4 -well plastic plates (NunClon). Finally, they were grown to confluence $(\sim 1$ week), and the medium was changed twice each week until the experiments were performed.

\section{CX43-/ - and $C \times 43+/+$ astrocyte cultures}

$\mathrm{Cx} 43$-deficient $(\mathrm{Cx} 43-/-)$ and wild-type $(\mathrm{Cx} 43+/+)$ astrocyte cultures were prepared from the cortex of newborn $\mathrm{Cx} 43$-deficient mice, as de- scribed above for OF1 mice. The mouse genotype was determined by PCR analysis. Briefly, mouse tissue samples were digested in buffer (10 mм Tris- $\mathrm{HCl}$, pH 8.0, $50 \mathrm{~mm} \mathrm{KCl,} 1.5 \mathrm{~mm} \mathrm{MgCl}_{2}, 0.45 \%$ IGEPAL CA630, 0.45\% Tween 20) containing Proteinase K (500 $\mu \mathrm{g} / \mathrm{ml}$; Promega, Madison, WI) at $56^{\circ} \mathrm{C}$ overnight. After digestion, $1 \mu \mathrm{l}$ of supernatant containing mouse DNA was added to $24 \mu \mathrm{l}$ of primer solution (1:1000 in pure water). Two sets of primers were used: one for the Cx43 wild-type gene, a 22 mer forward oligonucleotide and a 25 mer reverse oligonucleotide (5'-CCCCACTCTCACCTATGTCTCC-3' and 5' -ACTTTTGCGCCTAGCTAGCTATCCC- $3^{\prime}$, respectively); the second for the LacZ insert, a 22 mer forward oligonucleotide and a 22 mer reverse oligonucleotide (5'-GGCATACAGACCCTTGGACTCC-3' and 5' -TGCGGGCCTCTTCGCTATTACG-3', respectively). The PCR was achieved using a "PCR ready to go" kit (GE Healthcare, Saclay, France) with the solution described above, following the instructions of the kit. DNA was first annealed at $94^{\circ} \mathrm{C}$ and then amplified at $55^{\circ} \mathrm{C}$ for 40 cycles. The PCR products were analyzed by electrophoresis in a $2 \%$ agarose gel stained with ethidium bromide (Sigma-Aldrich). The specific amplified sequences were 550 and $850 \mathrm{bp}$ long for the mutant gene and wild-type gene, respectively.

\section{Microglial cells, MG-astrocytes cocultures, and} conditioned medium

Cerebral hemispheres were dissected from newborn mice [postnatal day 1 (P1)] after removing the meninges. After dissociation, cells were seeded into 100 -mm-diameter culture dishes (NunClon) at $3 \times 10^{6} \mathrm{cells} / 10 \mathrm{ml} /$ dish in DMEM, containing 10\% heat-inactivated FCS (Abcys, Paris, France), as described previously by Calvo et al. (2000). The medium was changed at 1 and 3 DIV, and cells were collected at 10 DIV by shaking the culture dishes to detach cells adherent to the astrocyte monolayer. The collected population resulted in $>98 \%$ of cells bearing the Mac- 1 antigen, a specific marker of mononuclear cells (Calvo et al., 2000). Freshly collected MG were used either to be seeded on confluent astrocytes (cocultures MG-astrocyte) or to make conditioned medium harvested from activated $\mathrm{MG}\left(\mathrm{CM}^{*}\right)$.

MG-astrocyte cocultures were obtained by the addition of MG $(3 \times$ $10^{5}$ cells $/ 16 \mathrm{~mm}$ wells or $10^{6}$ cells $/ 35 \mathrm{~mm}$ dishes) on confluent secondary astrocytes. Cocultures were maintained for $24 \mathrm{~h}$ in DMEM containing $5 \%$ FCS and then treated (or not for control) for another $24 \mathrm{~h}$.

To obtain $\mathrm{CM}^{*}$, freshly collected MG were seeded in DMEM containing $5 \%$ FCS $\left(1.7 \times 10^{6}\right.$ cells $/ \mathrm{ml} /$ dish in $35 \mathrm{~mm}$ dishes $)$ and treated with LPS (10 ng/ml, Escherichia coli strain; Sigma-Aldrich) for $6 \mathrm{~h}$. The resulting supernatants from activated MG were collected, filtered $(0.22 \mu \mathrm{m})$, and stored at $-20^{\circ} \mathrm{C}$ before used for experiments.

\section{Cell treatments}

MG-astrocyte cocultures were treated for $24 \mathrm{~h}$ with LPS at $10 \mathrm{ng} / \mathrm{ml}$, which induced an MG activation (Même et al., 2006), and then used for experiments. Astrocyte cultures were treated with either $\mathrm{CM}^{\star}$ (diluted four times as the final concentration) or the mix of cytokines IL- $1 \beta$ and TNF- $\alpha$ ( $10 \mathrm{ng} / \mathrm{ml}$ for each; Roche Diagnostics, Indianapolis, MI) for $24 \mathrm{~h}$ and then used for experiments. In all cases, control cells received no treatments. Hemichannel blockers niflumic acid (NF; $100 \mu \mathrm{M}$, SigmaAldrich) and gap26 and gap27 synthetic peptides (300 $\mu \mathrm{g} / \mathrm{ml}$; NeoMPS, Strasbourg, France) were coapplied with $\mathrm{EthBr}$ (for $10 \mathrm{~min}$ at $37^{\circ} \mathrm{C}$ ) (see below). The reducing agent dithiothreitol (DTT; $10 \mathrm{~mm}$; Sigma-Aldrich) was applied similar to the hemichannels blockers. SB202190 [4-(4fluorophenyl)-2-(4-hydroxyphenyl)-5-(4-pyridyl) $1 \mathrm{H}$-imidazole $] \quad$ (10 $\mu \mathrm{M}$; Sigma-Aldrich), a specific p38 mitogen-activated protein kinase (MAPK) inhibitor (Fukunaga and Hunter, 1997; Zhang et al., 2007), or L-name (1 mM; Sigma-Aldrich), a nitric oxide synthase (NOS) inhibitor, were coapplied with $\mathrm{CM}^{*}$ or the mix of cytokines, depending of the experiment.

\section{Scrape loading/dye transfer technique}

Gap junction permeability was determined at room temperature (20$22^{\circ} \mathrm{C}$ ) using the scrape-loading/dye transfer (SL/DT) technique, as described previously (Même et al. 2006), on either astrocyte cultures or MG-astrocyte cocultures. Briefly, experiments were performed by washing cells for $10 \mathrm{~min}$ in HEPES-buffered salt solution containing the fol- 
lowing (in mM): $140 \mathrm{NaCl}, 5.5 \mathrm{KCl}, 1.8 \mathrm{CaCl}_{2}, 1 \mathrm{MgCl}_{2}, 10$ glucose, 10 HEPES, pH 7.4. Cells were then washed in a $\mathrm{Ca}^{2+}$-free HEPES solution for $1 \mathrm{~min}$, and then scrape-loading was achieved with a razor blade in the same $\mathrm{Ca}^{2+}$-free solution containing the fluorescent dye Lucifer yellow $\mathrm{CH}$ (LY; $1 \mathrm{mg} / \mathrm{ml}$; Sigma). After $1 \mathrm{~min}$, LY was washed out several times with the HEPES buffer salt solution. Eight minutes after scraping, fluorescent images were captured using an inverted fluorescent microscope equipped for epifluorescence (Diaphot-Nikon, Tokyo, Japan) and a camera connected to an image analysis system. For each trial, data were quantified by measuring fluorescence areas in five consecutive fields using an image analyzer system (Lucia-Nikon, Tokyo, Japan). Quantification of changes in GJC induced by different treatments was performed by measuring the fluorescence area, expressed as arbitrary units (AU), in different experimental conditions.

The analysis of the intercellular diffusion of the fluorescent derivative of glucose 2-NBDG (molecular weight, 342) was achieved by using the SL/DT technique as described above, except that the cells were briefly $(<15 \mathrm{~s})$ exposed to this compound just for the scraping and were then immediately washed off. In addition, fluorescent pictures were taken 4 min after loading to minimize leak of 2-NBDG resulting from permeability of the cell membrane to this compound. In this case, control experiments were performed in the same conditions with Lucifer yellow. 2 -NBDG solution $(5 \mathrm{mg} / \mathrm{ml})$ was prepared in the $\mathrm{Ca}^{2+}$-free solution and kept at $4^{\circ} \mathrm{C}$ until use (Blomstrand and Giaume, 2006).

\section{Dye uptake}

For visualization of dye uptake by captured images, cells were exposed to either $0.5 \mu \mathrm{M}$ EthBr or $500 \mu \mathrm{M}$ 2-NBDG (Invitrogen, Eugene, OR) for 10 min at $37^{\circ} \mathrm{C}$. Then, cells were washed with HBSS (in mM: $137 \mathrm{NaCl}, 5.4$ $\mathrm{KCl}, 0.34 \mathrm{Na}_{2} \mathrm{HPO}_{4}, 0.44 \mathrm{KH}_{2} \mathrm{PO}_{4}, \mathrm{pH} 7.4$ ) and supplemented with 1.2 $\mathrm{mm} \mathrm{CaCl}_{2}\left(\mathrm{HBSS}_{-\mathrm{Ca}^{2+}}\right)$. For EthBr uptake, astrocytes were mounted in Fluoromount and examined by epifluorescence (518 nm excitation and $605 \mathrm{~nm}$ emission) using an inverted microscope (Diaphot-Nikon) equipped with a CCD camera (Nikon) associated with image analyzer software (Lucia-Nikon). Captured images of EthBr uptake were analyzed with the NIH ImageJ program. For 2-NBDG uptake, astrocytes in HBSS$\mathrm{Ca}^{2+}$ were placed in a BX 51W1I upright microscope (Olympus Optical, Tokyo, Japan) with water immersion lenses equipped with an imaging system with a Retga 1300I fast-cooled monochromatic digital camera (12-bit) (QImaging, Burnaby, Canada) and a monochromator for fluorophore excitation. 2-NBDG was exited at $488 \mathrm{~nm}$, and the emission was filtered at 505-550 nm (Porras et al., 2004). In each experiment, the resulting fluorescence was measured with Metafluor software (Universal Imaging, Downingtown, PA), and for each value, the background value was subtracted.

For time lapse fluorescence imaging, fluorescence signals from cells bathed with HBSS-Ca ${ }^{2+}$ containing $5 \mu \mathrm{M}$ EthBr were recorded every $30 \mathrm{~s}$ using the same microscope (Olympus BX 51W1I). To test for changes in slope, regression lines were fitted to points before and after various treatments using the Microsoft (Seattle, WA) Excel program, and mean values of slopes were compared using Graphpad Software (San Diego, CA).

\section{Biotinylization}

After treatments, confluent cells cultured in 100-mm-diameter dishes were washed three times with HBSS-Ca ${ }^{2+}$. Three milliliters of SulfoNHS-SS-biotin $\left(0.5 \mathrm{mg} / \mathrm{ml}\right.$ dissolved in HBSS- $\left.\mathrm{Ca}^{2+}\right)$ were added to the cell culture and incubated for $30 \mathrm{~min}$ at $4^{\circ} \mathrm{C}$. Cells were washed three times with HBSS-Ca ${ }^{2+}$ solution plus $15 \mathrm{~mm}$ glycine, $\mathrm{pH}$ 8.0, to quench unreacted biotin, and they were harvested by scraping with a rubber policeman in the presence of protease inhibitors $(200 \mu \mathrm{g} / \mathrm{ml}$ soybean trypsin inhibitor, $1 \mathrm{mg} / \mathrm{ml}$ benzamidine, $1 \mathrm{mg} / \mathrm{ml} \varepsilon \varepsilon$-aminocaproic acid, and $2 \mathrm{~mm}$ PMSF) and phosphatase inhibitors (see below, Western blot analysis). Then, cells were pelleted and lysed by sonication in $50 \mu \mathrm{l}$ of ice solution containing proteases and phosphatases inhibitors. The immobilized NeutrAvidin was added to the samples ( $1 \mu$ l of NeutrAvidin per 3 $\mu \mathrm{g}$ of biotinylated protein, assuming that $40 \%$ of total membrane protein was biotinylated), and the mixture was maintained for $1 \mathrm{~h}$ at $4^{\circ} \mathrm{C}$. One milliliter of binding buffer (HBSS, pH 7.2, plus $0.1 \%$ SDS and 1\% NP-40) was added, mixed by vortex, and centrifuged for $2 \mathrm{~min}$ at 14,000 rpm at $4^{\circ} \mathrm{C}$, and the supernatant was removed. The wash procedure described previously was repeated three times. In the final wash, the supernatant was removed, and $40 \mu \mathrm{l}$ of HBSS, $\mathrm{pH} 2.8$, plus $0.1 \mathrm{M}$ glycine were added to the pellet, mixed gently, and centrifuged at $14,000 \mathrm{rpm}$ for $2 \mathrm{~min}$ at $4^{\circ} \mathrm{C}$. The supernatant was removed and placed in a $1.5 \mathrm{ml}$ Eppendorf (Westbury, NY) tube, and $\mathrm{pH}$ was adjusted to 7.4 immediately by adding $10 \mu \mathrm{l}$ of $1 \mathrm{~m}$ Tris, $\mathrm{pH}$ 7.4. Relative levels of $\mathrm{Cx} 43$ present in each sample were measured by immunoblotting.

\section{Western blot analysis}

Cultures were rinsed twice with PBS, pH 7.4, and harvested by scraping with a rubber policeman in ice solution containing protease and phosphatase inhibitors ( $1 \mathrm{~mm}$ orthovanadate, $10 \mathrm{~mm} \alpha$-glycerophosphate) and complete miniprotease inhibitor (Roche Diagnostics). Proteins were measured in aliquots of cell lysates with the Bio-Rad protein assay (BioRad, Richmond, CA). Pelleted cells were resuspended in $40 \mu \mathrm{l}$ of the protease and phosphatase inhibitor solution, placed on ice, and lysed by sonication (Ultrasonic cell disrupter, Microson, Ultrasons, Annemasse, France). Then, samples were stored at $-80^{\circ} \mathrm{C}$ or analyzed by immunoblotting, as described previously. Aliquots of cell lysates (50 $\mu \mathrm{g}$ of protein) or total biotinylated surface membrane proteins were resuspended in a final concentration of $1 \times$ Laemli's sample buffer, boiled for $5 \mathrm{~min}$, separated on $8 \%$ SDS-PAGE and electro-transferred to nitrocellulose sheets as described previously. Nonspecific protein binding was blocked by incubation of nitrocellulose sheets in PBS-BLOTTO (5\% nonfat milk in PBS) for $30 \mathrm{~min}$, and then blots were incubated with primary antibody for $1 \mathrm{~h}$ at room temperature or overnight at $4^{\circ} \mathrm{C}$, followed by four $15 \mathrm{~min}$ PBS washes. Blots were incubated with goat anti-rabbit antibody conjugated to horseradish peroxidase. Immunoreactivity was detected by ECL detection using the SuperSignal kit (Pierce, Rockford, IL) according to instructions.

\section{Immunofluorescence and confocal microscopy}

For all immunostaining experiments, cells grown on coverslips were fixed at room temperature with $2 \%$ paraformaldehyde for $30 \mathrm{~min}$ and then washed three times with PBS. They were incubated in $0.1 \mathrm{M}$ PBSglycine, three times for $5 \mathrm{~min}$ each, and then in $0.1 \%$ PBS-Triton X-100 containing 10\% normal goat serum (NGS; Zymed, San Francisco, CA) for $30 \mathrm{~min}$.

To identify astrocytes versus MG, we used a specific molecular marker of each (GFAP and isolectin B4, respectively). We first incubated cells for $2 \mathrm{~h}$ at room temperature (RT) with anti-GFAP monoclonal antibody (IgG1, 1:500; ICN Chemicals, Irvine, CA) diluted in 0.1\% PBS-Triton X-100 with $2 \%$ NGS. After three rinses in $0.1 \%$ PBS-Triton X-100, cells were then incubated for $50 \mathrm{~min}$ at RT with both goat anti-mouse Alexa Fluor 488 (1:1500; Invitrogen) and isolectin GS-IB4 (1:100; Invitrogen), diluted in the same solution as the first antibody. To colabel $\mathrm{Cx} 43$ and GFAP, the rabbit anti-Cx43 Ab (BD Biosciences, Franklin Lakes, NJ) was incubated together with the mouse anti-GFAP $\mathrm{Ab}$, as described previously (Même et al., 2006). After three washes, cells were incubated for 50 min at RT with tetramethylrhodamine isothiocyanate-conjugated goat anti-rabbit IgG (1:1500; Southern Biotech, Birmingham, AL) and goat anti-mouse Alexa Fluor 488.

After several washes, coverslips were mounted in Fluoromount and examined by epifluorescence. To determine the astrocyte/MG ratio, cells were examined in a confocal laser-scanning microscope (TBCS SP2; Leica, Wetzlar, Germany) with a $63 \times$ objective. Stacks of consecutive confocal images taken at $500 \mathrm{~nm}$ intervals were acquired sequentially with two lasers (argon $488 \mathrm{~nm}$ and helium/neon $543 \mathrm{~nm}$ ), and $\mathrm{Z}$ projections were reconstructed using Leica confocal software.

\section{Electrophysiology}

Before electrophysiological measurements were performed, control and treated confluent astrocyte cultures were dissociated with trypsin-EDTA (Invitrogen), replated $\left(2 \times 10^{5}\right.$ cells per well), and grown on coverslips for $2-3 \mathrm{~h}$. This treatment yielded astrocytes with a rounder shape that facilitated the whole-cell patch recordings and did not alter the $\mathrm{CM}^{*}$ effect on the EthBr uptake (see Fig. $7 d$ ). Then, cells were transferred to an experimental chamber mounted on the stage of an inverted microscope (Olympus IX-51; Olympus Optical). For whole-cell experiments, bath 
solution contained the following (in mM): 140 $\mathrm{NaCl}, 5.4 \mathrm{KCl}, 1 \mathrm{MgCl}_{2}, 1.8 \mathrm{CaCl}_{2}, 2 \mathrm{BaCl}_{2}, 10$ HEPES, pH 7.4. The pipette solution contained the following (in mM): $130 \mathrm{CsCl}, 10 \mathrm{AspNa}, 0.26$ $\mathrm{CaCl}_{2}, 1 \mathrm{MgCl}_{2}, 2$ EGTA, 7 TEA-Cl, 5 HEPES, $\mathrm{pH}$ 7.2. Whole-cell currents were recorded as described previously (Contreras et al., 2003). Briefly, patch pipettes were made from borosilicate glass capillaries using a flaming/brown micropipette puller (P-87; Sutter Instruments, Union City, CA). The tip resistance was 5-10 $\mathrm{M} \Omega$ when filled with pipette solution. Currents were filtered at $1 \mathrm{kHz}$ and sampled at $5 \mathrm{kHz}$. Then, records were filtered with a digital lowpass filter of $0.5 \mathrm{kHz}$. Data acquisition and analysis were performed using pClamp 9 (Molecular Devices, Novato, CA).

\section{Statistical analysis}

For each data group, results are expressed as mean $\pm \mathrm{SE}$, and $n$ refers to the number of independent experiments. For statistical analysis, each treatment was compared with its respective control, and significance was determined using a one-way ANOVA followed in case of significance by a Tukey post hoc test. All statistical analyses were performed on raw data, even when percentages are given throughout this paper; differences were considered significant at ${ }^{*} p<0.05$, ${ }^{* *} p<0.01$, and ${ }^{* *} p<0.001$.

\section{Results}

Activated microglia reduce intercellular communication via gap junctions and increase hemichannel activity

in astrocytes

Because LPS-activated MG inhibit intercellular dye transfer via gap junction channels in cultured astrocytes (Même et al., 2006), we studied whether LPSactivated MG can also affect the activity of $\mathrm{Cx} 43$ hemichannels. For this purpose, EthBr uptake was investigated in astrocytes cocultured with MG. Immunostaining with astrocyte and MG markers (GFAP and isolectin B4, respectively) indicated that primary cultures of astrocytes were composed by $98.4 \pm 0.1$ and $1.6 \pm 0.1 \%$ GFAP-positive (red cells) and isolectin B4-positive (green cells) cells, respectively ( $n=3$ for each), whereas in cocultures, this proportion reached to $88.4 \pm 0.1$ and $11.6 \pm 2.6 \%(n=3$ for each $)$, respectively (Fig. $\left.1 a_{1-4}\right)$.

The SL/DT technique was used to quantify the gap junctionmediated intercellular diffusion of LY in astrocytes. Under control conditions, pure astrocyte cultures showed a fluorescent area of $48.3 \pm 2.5 \mathrm{AU}$ (a representative way to quantify the dye coupling) (Fig. $1 a_{5}, b$, white bar). Twenty four hours after LPS (10 $\mathrm{ng} / \mathrm{ml})$, addition to astrocyte cultures dye coupling was reduced $24 \pm 2 \%\left(n=3 ;{ }^{* *} p<0.01\right)$ (Fig. $\left.1 a_{6}, b\right)$. In MG-astrocyte cocultures, under control conditions (resting MG), no significant changes in dye coupling were detected ( $7 \pm 4 \%$ reduction; $n=3$; $p>0.05$ ) (Fig. $1 a_{7}, b$ ), compared with pure astrocyte cultures. However, $24 \mathrm{~h}$ after the addition of LPS $(10 \mathrm{ng} / \mathrm{ml})$ to these cocultures, the dye transfer was significantly reduced by $56 \pm 7 \%$ $\left(n=3 ;{ }^{* *} p<0.001\right)$ compared with untreated cocultures (Fig. $\left.1 a_{8}, b\right)$. This reduction was also statistically significant compared with the weak reduction induced by LPS in astrocytes cultures alone $\left({ }^{\delta \delta \delta} p<0.001\right)$.

In parallel, and as demonstrated previously (Contreras et al., 2002; Retamal et al., 2006, 2007), EthBr uptake was taken as an index of the activity of $\mathrm{Cx}$ hemichannels in astrocytes. Under control conditions, in the presence of external calcium, only a few cells from highly enriched astrocyte cultures (pure cultures) exhibited prominent EthBr uptake (18.3 $\pm 4.4 \mathrm{EthBr}$ cells/field; $n=$ 10) (Fig. $\left.1 a_{9}\right)$ and $24 \mathrm{~h}$ treatment with LPS $(10 \mathrm{ng} / \mathrm{ml})$ increased by approximately twofold the number of cells that present EthBr uptake $\left(84 \pm 10 \% ; n=3 ;{ }^{*} p<0.01\right)$ (Fig. $\left.1 a_{10}, c\right)$. Addition of MG on confluent astrocyte cultures and cocultured for $48 \mathrm{~h}$ did not induce dye uptake increase in astrocytes $(5 \pm 1 \%$ high over control value; $n=3$, n.s.) (Fig. $\left.1 a_{11}, c\right)$. However, treatment with LPS $(10 \mathrm{ng} / \mathrm{ml})$ for $24 \mathrm{~h}$ significantly increased EthBr uptake in astrocytes cocultured with MG $(439 \pm 20 \%)\left(n=3\right.$; $^{* \star *} p<$ 0.001) (Fig. $1 a_{12}, c$ ).

To determine whether the detected astrocyte permeabiliza- 


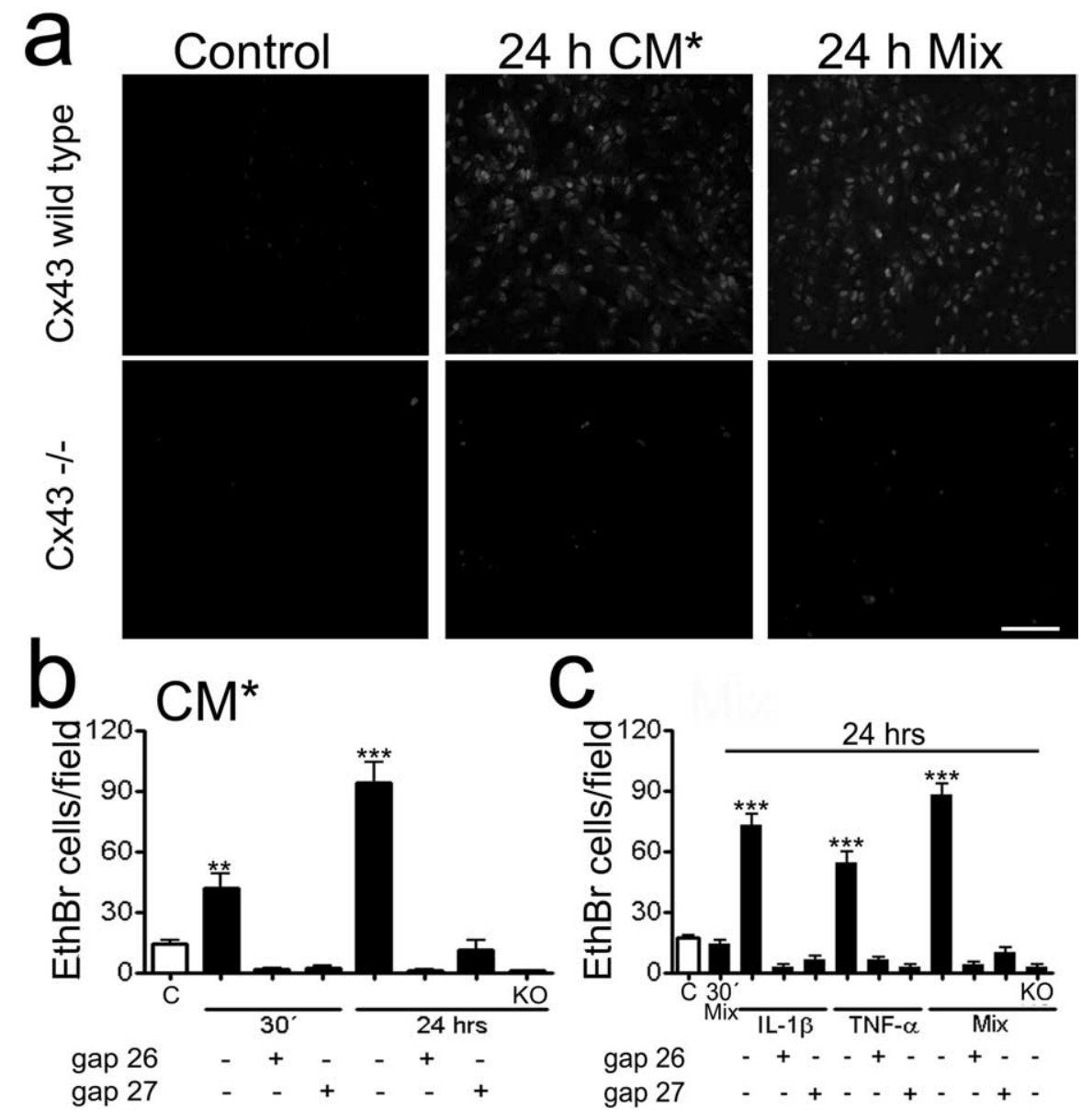

Figure 2. The increased EthBr permeability induced in astrocytes by conditioned medium from LPS-activated MG or TNF- $\alpha$ and IL-1 $\beta$ is sensitive to Cx43 hemichannel blocking peptides and is absent in Cx43-/- astrocytes. $\boldsymbol{a}$, Snapshot representative pictures of fluorescent fields showing the increase of EthBr-stained nuclei observed in astrocytes cultured from Cx43 wild-type mice, but not in astrocytes from Cx43-/- mice, after $24 \mathrm{~h}$ application of either CM* or Mix. Scale bar, $100 \mu \mathrm{m} . \boldsymbol{b}, \boldsymbol{c}, \mathrm{Graphs}$ representing the number of EthBr-positive astrocytes after treatments with $\mathrm{CM}^{*}(\boldsymbol{b})$, TNF- $\alpha$, IL-1 $\beta$, or Mix (c) for $30 \mathrm{~min}$ or $24 \mathrm{~h}$ applied on astrocyte cultures. During the 10 min incubation with EthBr, cells were coincubated in the presence $(+)$ or absence $(-)$ of the mimetic peptides gap26 or gap27 $(300 \mu \mathrm{g} / \mathrm{ml})$, for each proinflammatory treatment $(\boldsymbol{b}, \boldsymbol{c})$. Each plotted value represents the mean \pm SEM of at least three independent experiments. ${ }^{* *} p<0.01$ and ${ }^{* * *} p<0.001$, compared with the untreated astrocyte group (C).

tion induced by LPS-activated MG was mediated by the opening of Cx43 hemichannels, we used specific mimetic peptides, which act at the level of the second extracellular loops of Cx43 (Evans et al., 2006). Gap 26 and gap 27, used at a concentration of 300 $\mu \mathrm{g} / \mathrm{ml}$, significantly blocked the membrane permeability induced by activated MG (to $62 \pm 18$ and $55 \pm 29 \%$ of the control value; $n=3$ for each peptide, respectively; $p<0.001$ ) (data not shown). These data suggest that hemichannels constituted by $\mathrm{Cx} 43$ are the main pathway responsible for EthBr uptake in astrocytes induced by activated MG and that $\sim 45 \%$ of basal dye uptake is mediated by $\mathrm{Cx} 43$ hemichannels.

\section{Conditioned medium from LPS-activated MG or proinflammatory cytokines enhances astrocyte uptake through $\mathrm{Cx} 43$ hemichannels}

Recently, gap junction channels and hemichannels constituted by $\mathrm{Cx} 43$ were reported to be differentially regulated in C6 glioma cell lines (De Vuyst et at., 2007) and Cx43 hemichannels were shown to be sensitive to proinflammatory treatments in astrocytes (Morita et al., 2007). In addition, 24 h treatment with either conditioned medium harvested from LPS-activated MG $\left(\mathrm{CM}^{\star}\right)$ or the mixture of TNF- $\alpha$ and IL-1 $\beta$ (Mix) has been shown to decrease GJC in primary cultures of mice astrocytes (Même et al., 2006). Accordingly, the effect of these proinflammatory treatments at concentrations previously shown to be effective on gap junction channels (Même et al., 2006) was investigated on the activity of Cx43 hemichannels in astrocytes through the EthBr uptake. Twenty-four hour exposure of enriched astrocyte cultures from OF1 mice, to either diluted (1/4) $\mathrm{CM}^{*}$ (Fig. 2a, $24 \mathrm{~h} \mathrm{CM}{ }^{\star}$ ) or Mix (Fig. $2 a, 24 \mathrm{~h}$ Mix) induced a prominent increase in EthBr uptake compared with untreated control conditions (Fig. 2a, Control). The effect of Mix was dose dependent, because $24 \mathrm{~h}$ exposure to $0.1,1.0$, and $10.0 \mathrm{ng} / \mathrm{ml}$ induced an increase in EthBr uptake of 300,386 , and 505\% $(n=3)$, respectively. In contrast, the same treatments resulted in a significant decrease of GJC through Cx43 gap junction channels, observed using the SL/DT technique (see Fig. 5a). Under all conditions, EthBr uptake appeared heterogeneous, because dye uptake occurred in clusters of astrocytes, characterized by high fluorescence levels in the cells at the center of the cluster, surrounded by cells with variable fluorescence level (data not shown). This pattern of fluorescence was interpreted as the result of an initial dye uptake in subpopulations of astrocytes, followed by a secondary dye transfer to coupled neighboring cells; therefore, although GJC is inhibited, there is still a remaining dye coupling between treated astrocytes (Fig. $1 a_{8}$ ). However, only the most brilliant EthBr nucleus population was analyzed. In astrocytes cultured from Cx43-/- mice, 24 h treatment with either diluted $\mathrm{CM}^{*}$ (Fig. $2 a, \mathrm{Cx} 43-/-, 24 \mathrm{~h}$ $\mathrm{CM}^{\star}$ ) or Mix (Fig. 2a, Cx43-/-, $24 \mathrm{~h}$ Mix) did not increase the EthBr uptake showed under control conditions (Fig. 2a, Cx43-/-, Control). This observation demonstrates that the astrocyte permeabilization occurred specifically through Cx43 hemichannels.

Quantification of the experiments revealed that under control conditions, a low number of astrocytes exhibited EthBr uptake $(14.2 \pm 1.6 \mathrm{EthBr}$ cells/field; $n=9)$ (Fig. $2 b)$. Interestingly, after 30 min exposure to diluted $\mathrm{CM}^{\star}$, the number of cells showing EthBr uptake significantly increased by $290 \pm 18 \%\left({ }^{* *} p<0.01\right.$; $n=7$ ) (Fig. $2 b$ ). This increased permeability was drastically reduced by the mimetic peptides gap 26 (to $10 \pm 0.6 \%$ of the control value; $n=3 ;{ }^{* * *} p<0.001$ ) and gap 27 (to $15 \pm 0.6 \%$ of the control values; $n=3 ;{ }^{* * *} p<0.001$ ) (Fig. 2b). The number of EthBr-positive nuclei of astrocytes exposed for $24 \mathrm{~h}$ to $\mathrm{CM}^{\star}$ increased to $660 \pm 20 \%(n=9)$ compared with that observed in control astrocytes (Fig. $2 b)\left({ }^{* * *} p<0.001\right)$. Again, as illustrated in Figure $2 b$, this increase was blocked by both gap 26 (to $10 \pm 0.3 \%$ of the control value; $n=3 ;{ }^{* *} p<0.001$ ) (Fig. $2 b$ ) and gap 27 (to $23 \pm 10 \%$ of the control values; $n=3 ;{ }^{* *} p<0.001$ ) (Fig. $2 b$ ). It can be noted that mimetic peptides reduced the number of cells 
presenting EthBr uptake to values smaller than those observed under control conditions, suggesting that the main entrance for EthBr to the cells under these conditions is through $\mathrm{Cx} 43$ hemichannels. Furthermore, this increase in EthBr uptake was significantly abolished by $100 \mu \mathrm{M}$ niflumic acid, a blocking agent of Cx hemichannels that does not affect pannexin hemichannels (Bruzzone et al., 2005), not statistically different from those observed under control conditions (only a $11 \pm 16 \%$ over control values; $n=4$, n.s.) (data not shown). $\mathrm{CM}^{\star}$ did not affect the dye uptake of astrocytes $\mathrm{Cx} 43-/-(6 \pm 1 \%$ of the value measured in $\mathrm{Cx} 43+/+$ astrocytes; $n=3$ ) (Fig. $2 b$ ). Finally, neither treatment with gap 26 nor gap 27, used at similar concentrations as above, resulted in modifications of GJC in astrocytes when applied for 10 min (data not shown).

In contrast with that observed with $\mathrm{CM}^{*}, 30$ min exposure to Mix did not increase the number of astrocytes showing dye uptake. Indeed, it reduced slightly the number of cells presenting EthBr uptake ( $88 \pm 6 \%$ of the control value; $n=9$; ${ }^{\star} p<0.05$ ) (Fig. $2 c$ ). In contrast, $24 \mathrm{~h}$ incubation with either IL- $1 \beta$ or TNF- $\alpha$ increased significantly the number of astrocytes showing EthBr uptake ( $455 \pm 8$ and $313 \pm 9 \%$, respectively; $n=9$ for each condition; ${ }^{\star *} p<0.001$ ) (Fig. $2 c$ ). The effect of IL- $1 \beta$ was significantly higher than that of TNF- $\alpha\left({ }^{*} p<0.05\right)$. Such difference in the short-term effect of $\mathrm{CM}^{\star}$ and Mix could be attributable to the fact that in the $\mathrm{CM}^{\star}$ active compounds, other than IL- $1 \beta$ and TNF- $\alpha$, could be present and contribute to the activation process. The effect of each cytokine was totally blocked by both mimetic peptides: gap 26 ( $17 \pm 0.2$ and $43 \pm 0.8 \%$ of the control value for IL- $1 \beta$ and TNF- $\alpha$, respectively; $n=3$ for each; $\left.{ }^{* *} p<0.001\right)$, or gap 27 (42 \pm 0.7 and $19 \pm 0.5 \%$ of the control value for IL- $1 \beta$ and TNF- $\alpha$, respectively; $n=3$ for each; ${ }^{\star *} p<0.001$ ) (Fig. $2 c$ ). Twenty-four hour treatment with Mix produced a significant increase in EthBr uptake, higher than that induced by each cytokine alone (506 $\pm 6 \%$ of the control value; $n=9 ;{ }^{* * *} p<0.001$ ) (Fig. 2c). Similar to that observed for cytokines alone, the enhanced effect of Mix was blocked by the two mimetic peptides: gap $26(21 \pm 4.2 \%$ of the control value; $n=3)$ or gap $27(57 \pm 2 \%$ of the control value; $n=3$ ) (Fig. $2 c$ ). Finally, the Mix-induced dye uptake was not observed in $\mathrm{Cx} 43-/-$ astrocytes $(16 \pm 5 \%$ of the $\mathrm{Cx} 43+/+$ control value) (Fig. $2 c$ ). Moreover, the number of astrocytes showing EthBr uptake was not different from that observed in the presence of peptide blockers $(p>0.05)$.

Because changes in dye uptake measured in captured images represent only a single time point in EthBr uptake of a cell population, we performed dynamic measurements of dye uptake at a single cell level using time lapse measurements to gain additional quantitative data of the phenomenon. Astrocytes exposed to either $\mathrm{CM}^{\star}$ (Fig. $3 a$, filled circles corresponding to the average of 20 cell per experiment) $(n=10)$ or Mix for $24 \mathrm{~h}$ (Fig. $3 a$, gray circles corresponding to the average of 20 cells per experiment) $(n=10)$ presented a higher rate of EthBr uptake compared with untreated astrocytes (Fig. 3a, empty circles corresponding to the average of 20 cells per experiment $(n=10)$. The analysis of these data revealed that $\mathrm{CM}^{\star}$ - and Mix- treated astrocytes present a $271 \pm$ 27 and $279 \pm 33 \%$ increased rate of dye uptake, respectively (Fig. $3 b)\left({ }^{* *} p<0.01\right.$ for each). As illustrated in Figure $3 b$, under all conditions studied, including control, the dye uptake was drastically inhibited by $\mathrm{La}^{3+}(200 \mu \mathrm{M})$, which is known to block specifically Cx but not pannexin hemichannels (Bruzzone et al., 2005; Pelegrin and Surprenant, 2006). Indeed, the application of $200 \mu \mathrm{M} \mathrm{La}^{3+}$ decreased the rate of EthBr uptake (Fig. 3a) to values near $\left(\mathrm{CM}^{\star}, 12 \pm 3.6 \%\right.$ of the control value; $n=10 ;{ }^{\star *} p<$ 0.01 ) or even below (Mix, $63 \pm 21 \%$ of control value; $n=5$;
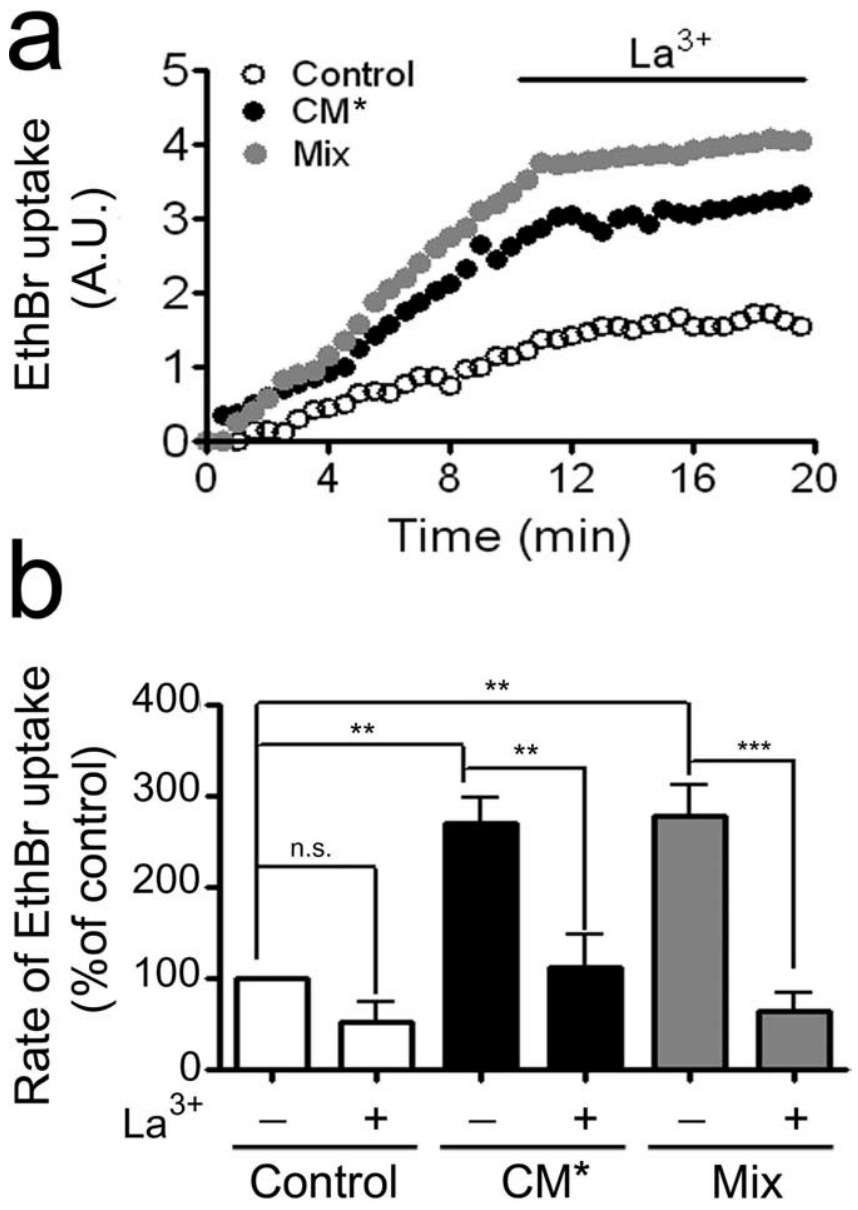

Figure 3. Treatment of astrocytes with conditioned medium harvested from LPS-activated MG or proinflammatory cytokines increases membrane permeability of astrocytes through $\mathrm{X} 43$ hemichannels. $\boldsymbol{a}$, Representative time lapse of EthBr uptake in astrocytes recorded every $30 \mathrm{~s}$. Each circle corresponds to one EthBr uptake determination, averaged with 20 recorded cells, measured either under untreated condition (Control; empty circles) or after $24 \mathrm{~h}$ incubation with either $\mathrm{CM}^{*}\left(\mathrm{CM}^{*}\right.$; filled circles) or Mix (Mix; gray circles) in astrocyte cultures. For each group, $\mathrm{La}^{3+}(200 \mu \mathrm{m})$ was applied during the last $10 \mathrm{~min}$ of the EthBr uptake time lapse determination. $\boldsymbol{b}$, Quantification of the rate of EthBr uptake in astrocytes under untreated conditions (Control; empty bar) or treated with CM* (CM*; filled bar) or Mix (Mix; gray bar). Data are expressed as the percentage of the EthBr uptake rate measured under control conditions. For each group, the dye uptake rate was measured in the presence $(+)$ or absence $(-)$ of $\mathrm{La}^{3+}$ $(200 \mu \mathrm{M})$ at the end of the time lapse. Each bar represents the mean \pm SEM [except for the control ( - ) group taken as reference] of 10 independent experiments per group. ${ }^{* *} p<0.01$, ${ }^{* * *} p<0.001$; n.S., no significant difference, compared with the indicated groups.

${ }^{* * *} p<0.001$ ) the values observed under control conditions (Fig.
$3 b)$.

Because the open probability of $\mathrm{Cx} 43$ hemichannels is regulated by the intracellular redox state (Retamal et al., 2006, 2007) and cytokines such as IL- $1 \beta$ alter the redox state of astrocytes (Robinson et al., 1999), we tested the effect of DTT, a sulfhydrylreducing agent, on the $\mathrm{CM}^{\star}$ - and Mix-induced changes in astrocytes membrane permeability. Quantification of EthBr uptake indicated that DTT treatment $(10 \mathrm{~mm}, 10 \mathrm{~min})$ increased the rate of dye uptake $(160 \pm 25 \%)(n=3 ; p<0.001 ; 20$ cells analyzed per experiment) (data not shown) in astrocytes under control conditions consistent with its recently described effect on Cx43 hemichannels in cells under normoxic condition (Retamal et al., 2007). In contrast, and similar to what happens in metabolically inhibited astrocytes (Retamal et al., 2006), DTT significantly reduced the activity of $\mathrm{Cx} 43$ hemichannels in astrocytes pretreated 
either with $\mathrm{CM}^{\star}$ or Mix for $24 \mathrm{~h}$ (from $271 \pm 28 \%$ increase before DTT to $165 \pm 28$ and $93 \pm 6 \%$ of control values for $\mathrm{CM}^{*}$ and Mix after DTT, respectively; $n=5$; $p<0.05$ and $p<0.01$, respectively) (data not shown). The inhibitory effect of DTT suggests that NO, possibly through Cx43 S-nitrosylation, increases the hemichannel activity.

A p38 MAP kinase-dependent step is involved in the regulation of $\mathrm{Cx} 43$ hemichannel and gap junction channel permeability

It is well established that IL- $1 \beta$ and TNF- $\alpha$ induce p38 MAP kinase activation in astrocytes (Clerk et al., 1999; Rossa et al., 2006; Mitchell et al., 2007), which, in turn, can induce the expression of NOS (Gutierrez-Venegas et al., 2005; Xu et al., 2006) and, consequently, an increase in NO production (Guan et al., 1997; Badger et al., 1998). Accordingly, the effect of SB202190, a p38 MAP kinase inhibitor, and L-name, a NOS inhibitor, were investigated on the Mix-induced astrocyte permeabilization. Coaddition of $1 \mathrm{~mm}$ L-name with Mix (for $24 \mathrm{~h}$ ) reduced drastically the Mix-induced EthBr uptake measured 24 h later (76 $\pm 5 \%$ inhibition; $n=5 ;{ }^{* *} p<0.001$ ) (Fig. $4 a$, L-name, $b$ ). Similarly, coaddition of SB202190 (10 $\mu \mathrm{M})$ with Mix for $24 \mathrm{~h}$, reduced drastically the Mix-induced EthBr permeability ( $80 \pm 3 \%$ inhibition; $n=6{ }^{* * *} p<0.001$ ) (Fig. $\left.4 a, \mathrm{SB}, b\right)$. As in the time lapse experiment, the DTT treatment $(10 \mathrm{~mm}, 10 \mathrm{~min})$ significantly reduced the activity of $\mathrm{Cx} 43$ hemichannels in astrocytes $(93 \pm 6 \%$ reduction; $n=5 ;{ }^{* *} p<0.001$ ) (Fig. 4a, DTT, $b$ ).

Because p38 MAP kinase and NO are involved in the increase in membrane permeability induced by proinflammatory conditions, we assessed whether SB202190 and DTT also affect the reduction of astrocytic GJC induced by $\mathrm{CM}^{\star}$ or Mix. Under normal conditions, astrocytes are highly coupled (Fig. $5 a$, control), whereas a $24 \mathrm{~h}$ exposure to $\mathrm{CM}^{\star}$ or Mix reduced significantly the astrocytic GJC by $70 \pm 13$ and $63 \pm 8 \%$ for Mix and $\mathrm{CM}^{\star}$, respectively (Fig. $5 b, c)\left(n=7 ;{ }^{* *} p<0.001\right)$. When astrocytes were coincubated with Mix (or CM*) plus SB202190, the reduction in GJC was completely prevented (Fig. $5 a$ ). Indeed, the fluorescence area measured in the presence of the p38 inhibitor reached $105 \pm 15$ and $83 \pm 6 \%$ of the control values for the Mix and $\mathrm{CM}^{\star}$ treatment, respectively $(n=7 ; p>0.05)$ (Fig. $\left.5 b, c\right)$. In contrast, acute application of DTT $(10 \mathrm{~mm})$ did not recover the GJC inhibition induced by either Mix (Fig. 5a) or $\mathrm{CM}^{\star}$ (data not shown). In contrast, DTT seems to potentiate the GJC inhibition induced by Mix $\left(17 \pm 2 \%\right.$ of the control values; $n=5 ;{ }^{* *} p<$ $0.001)$ (Fig. $5 b)$ or $\mathrm{CM}^{\star}(16 \pm 4 \%$ of the control value; $n=5$; ${ }^{* *} p<0.001$ ) (Fig. 5c), although these latter effects were not statistically significant $(p>0.05)$.

Total and cell surface $\mathrm{Cx} 43$ levels are reduced by conditioned medium and proinflammatory cytokines

To elucidate whether the phenomena described above were associated with changes in Cx43 availability in different cellular compartments, the reactivity and cellular distribution of $\mathrm{Cx} 43$ was studied using indirect immunofluorescence in astrocytes under different conditions. After $24 \mathrm{~h}$ of Mix application to the cultures, the total $\mathrm{Cx} 43$ reactivity was drastically reduced compared with the control condition (Fig. 6a). The SB202190 or DTT did not prevent the Mix-induced decrease in Cx43 reactivity (Fig. 6a).

Because loss of $\mathrm{Cx} 43$ immunoreactivity might be the consequence of reduced $\mathrm{Cx} 43$ protein levels or $\mathrm{Cx} 43$ protein masking (Theriault et al., 1997), Western blot analysis confirmed that Mix reduced the total levels of $\mathrm{Cx} 43$, and that this change was not prevented by SB202190 or by DTT (Fig. 6b). Similarly, Cx43
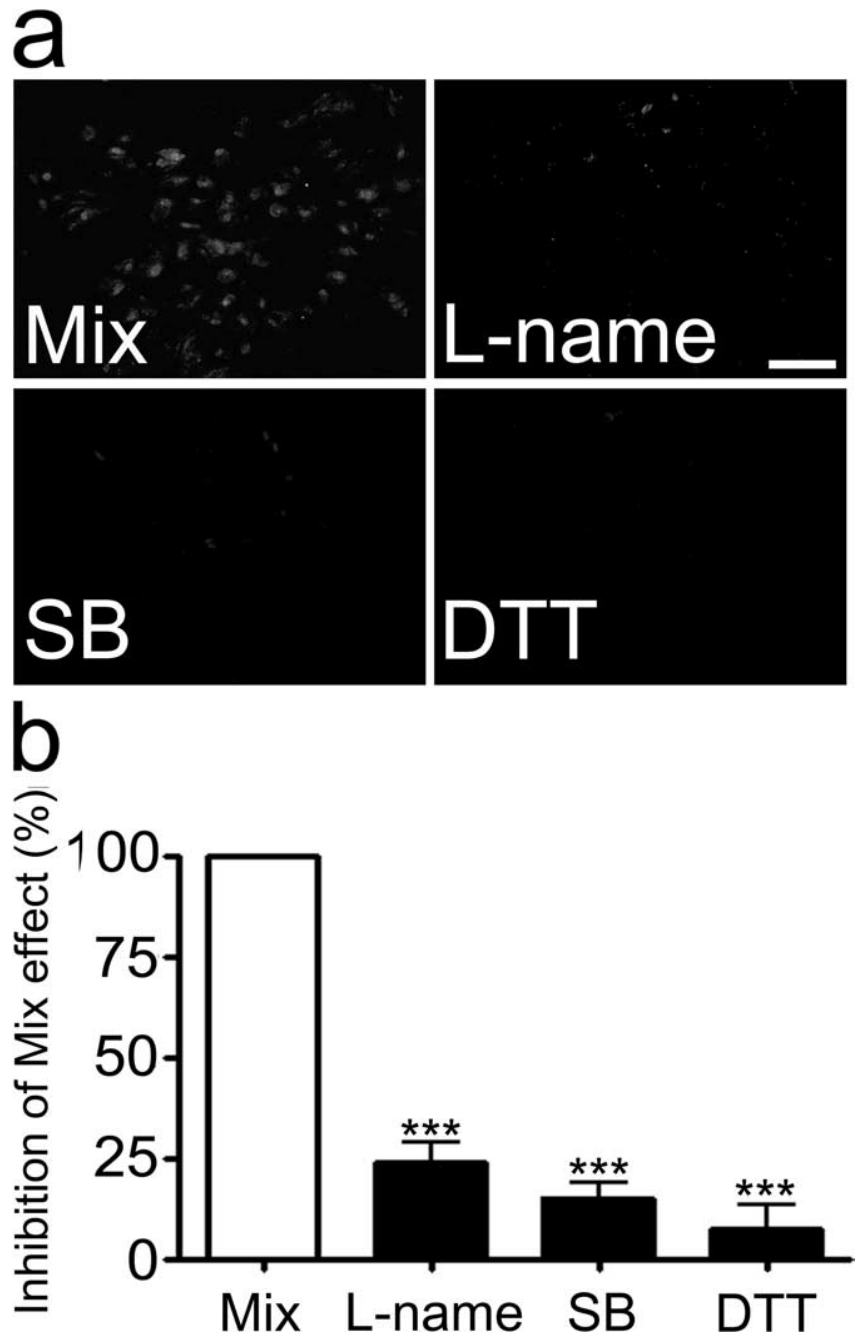

Figure 4. Inhibition of p38 MAP kinase or nitric oxide synthase prevents the Mix-induced membrane permeabilization through $(x 43$ hemichannels. $\boldsymbol{a}$, Representative captures images showing the EthBr uptake in astrocytes treated for $24 \mathrm{~h}$, either with Mix alone ( $\boldsymbol{a}, \mathrm{Mix}$ ) or in

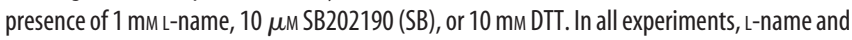
SB202190 were coapplied for $24 \mathrm{~h}$ with Mix, whereas DTT was applied 10 min before dye uptake assay. Scale bar, $50 \mu \mathrm{m} . \boldsymbol{b}$, Graph showing the inhibitory effect of L-Name, SB202190 (SB), and DTT on Mix-evoked dye uptake in astrocytes. Plotted data (mean \pm SEM excepted for Mix that is taken as reference) are expressed as percentage of inhibition of dye uptake and are obtained from independent experiments. ${ }^{* *} p<0.001$, compared with the Mix group.

located at the cellular surface was also reduced by $24 \mathrm{~h}$ treatment with Mix, and this reduction was not prevented by SB202190 (Fig. 6c). Under all conditions studied, the same amount of protein was used in each line. No phosphorylation state changes were detected when the Cx43 immunoblotting profile was analyzed for changes in the electrophoretic motility.

Unitary current events of $\mathrm{Cx} 43$ hemichannels are recorded in astrocytes treated with a proinflamatory condition

The unitary conductance value of $\mathrm{Cx} 43$ hemichannels induced to open with positive membrane potentials or zero extracellular $\mathrm{Ca}^{2+}$ concentration is $\sim 220 \mathrm{pS}$ (Contreras et al., 2003). However, under resting conditions, the open probability of $\mathrm{Cx} 43$ hemichannels is very low, consistent with the low EthBr uptake rate (Contreras et al., 2003). Because the membrane potential of astrocytes under resting conditions is negative, we searched for $\mathrm{Cx} 43$ unitary events applying voltage ramps from -80 to $0 \mathrm{mV}$ 
using the whole-cell patch-clamp configuration (Fig. 7a). To facilitate whole-cell recording, astrocytes were rounded up as described in Materials and Methods and placed in the same culture medium in which they were cultured during the last $24 \mathrm{~h}$. In these cells, dye uptake was comparable with that observed in nontrypsinized astrocytes (compare Figs. $3 a$ and $7 d$ ). Moreover, in control cells, unitary events were not detected in eight cells (Fig. $7 b$ ), and only two showed single current event ( 2 of 10 cells recorded) (data not shown). In contrast, in cells incubated with $\mathrm{CM}^{*}$ for $24 \mathrm{~h}$, unitary current events were always observed (Fig. 7c). Point by point conversion of current to conductance values revealed a unitary conductance of $216.0 \pm 9.5 \mathrm{pS}(n=4)$ in all cells studied (4 of 4) (Fig. 7, right, bottom).

\section{Cx43 hemichannels are permeable to glucose}

Glucose is well known to be essential for a correct brain function, and its homeostasis is altered by inflammatory conditions (Yu et al., 1995; Battelino et al., 1999). Accordingly, we assessed whether the glucose flux, either between astrocytes themselves (through gap junction channels) or between extracellular medium and astrocytes (through hemichannels), is affected by $\mathrm{CM}^{\star}$ treatments. As recently reported by Blomstrand et al. (2006), under basal conditions, cultured astrocytes present an important metabolic coupling, as demonstrated by the high degree of 2-NBDG diffusion in the astrocyte monolayer (data not shown). Here, we demonstrated that a proinflammatory treatment decreased the intercellular 2-NBDG transfer. Indeed, SL/DT experiments indicated that $24 \mathrm{~h}$ treatment with $\mathrm{CM}^{\star}$ or Mix decreased the 2-NBDG diffusion by $30 \pm 4$ and $35 \pm 7 \%$ of the control values, respectively $(n=4 ; p<0.001)$ (data not shown). To test glucose influx through $\mathrm{Cx} 43$ hemichannels in proinflammatory-treated astrocytes, they were incubated with $\mathrm{CM}^{\star}$ for $24 \mathrm{~h}$ and finally incubated with 2-NBDG $(500 \mu \mathrm{M})$ for $10 \mathrm{~min}$. A fraction ( 25-50\%) of 2-NBDG uptake measured in astrocytes under control conditions was not significantly sensitive to $200 \mu \mathrm{M} \mathrm{La}{ }^{3+}(25 \pm 6 \%$ inhibition; $n=4$, n.s.; $p>0.05$ ) but significantly sensitive to 300 $\mu \mathrm{g} / \mathrm{ml}$ gap27 (47 $\pm 6 \%$ inhibition; $n=4 ;{ }^{\star} p<0.05$ ) (Fig. $8 b$ ). The hemichannel blocker-insensitive fraction was attributed to glucose entry through glucose transporters. The uptake of $2-N B D G$ was enhanced by $325 \pm 26 \%\left(n=4\right.$; $\left.{ }^{* * *} p<0.001\right)$ by $\mathrm{CM}^{\star}$ treatment (Fig. 8a,b). This increase of 2-NBDG uptake was near completely abolished by $\mathrm{La}^{3+}(66 \pm 9 \%$ reduction; $n=4$; ${ }^{* * *} p<0.001$ ) (Fig. 8). Similarly, the $\mathrm{CM}^{\star}$-evoked $2-\mathrm{NBDG}$ uptake increase was reduced by $300 \mu \mathrm{g} / \mathrm{ml}$ gap 27 (75 $\pm 5 \%$ inhibition; $n=4 ;{ }^{* *} p<0.001$ ) (Fig. $8 a, b$ ). These data demonstrate that proinflammatory treatments induce an increase in glucose uptake in astrocytes through Cx43 hemichannels. Taken as a whole, they indicate that inflammatory treatments increase the uptake capacities of astrocytes for glucose while they restrict its intercellular trafficking.
Mix
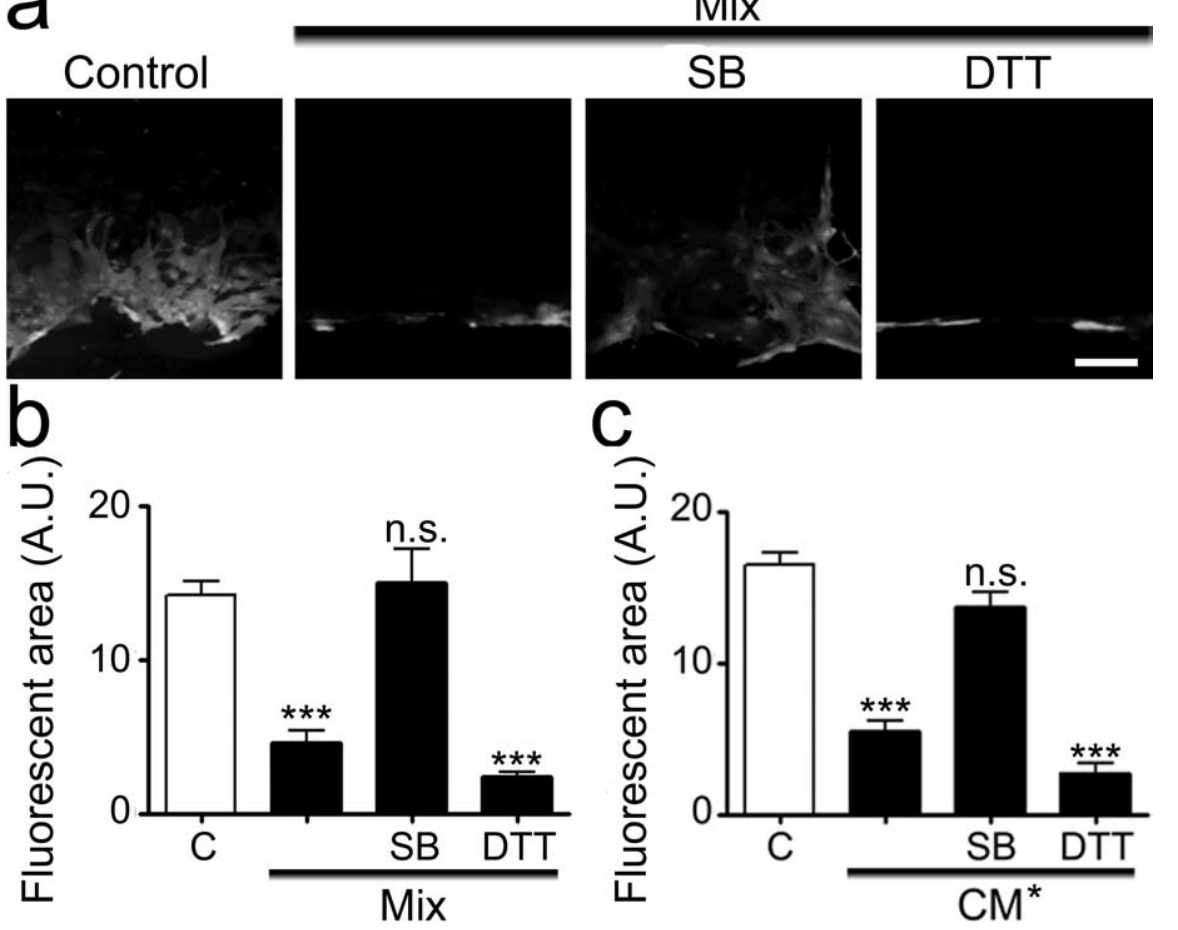

Figure 5. The Mix-induced inhibition of astrocytic GJC is prevented by the inhibition of p38 MAPK but not by lowering intra(diffusion of $L Y$ though GJC in confluent astrocyte cultures either unde ( SB) or $10 \mathrm{~mm}$ DTT and compared with untreated conditions as control. Each value, expressed in AU, corresponds to the mean \pm
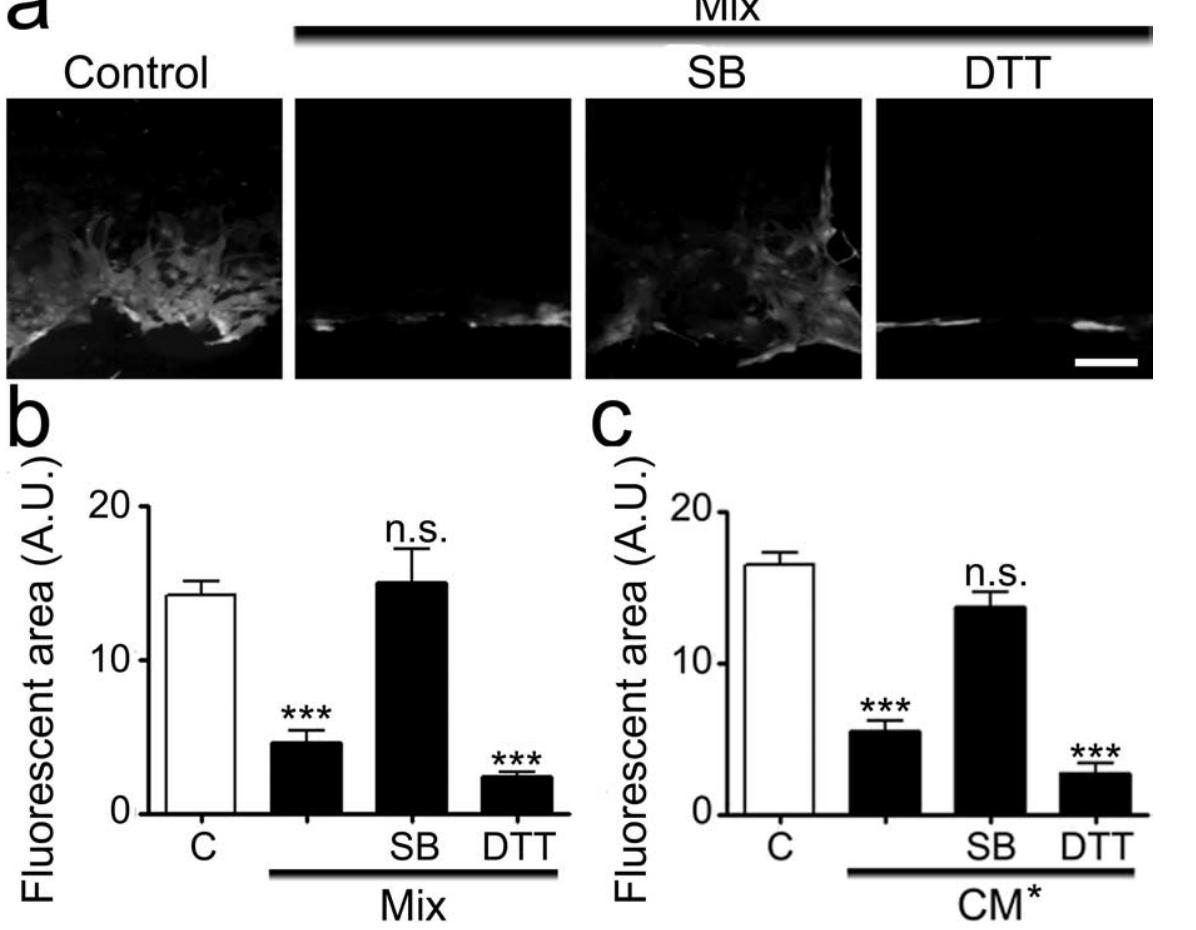

(1) 
a
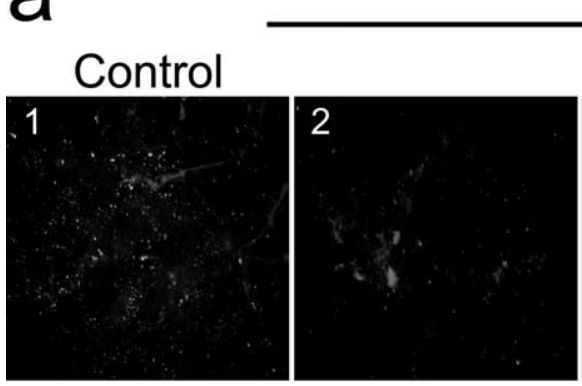

b

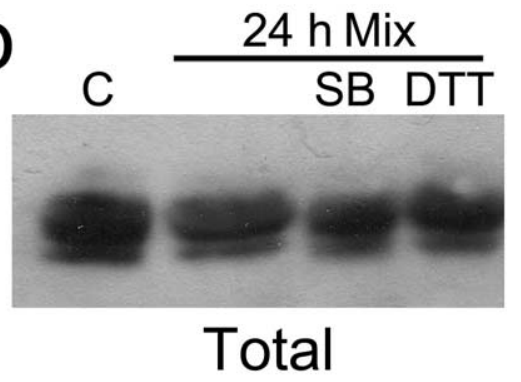

24 h Mix
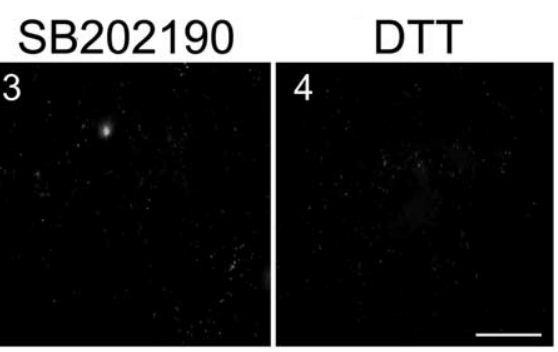

C

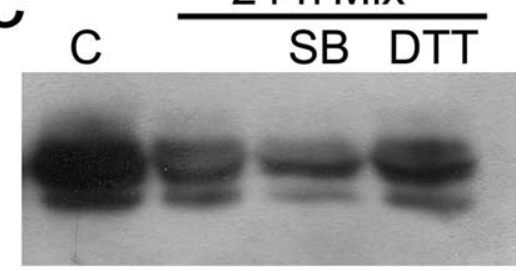

Biotinylated

Figure 6. The Mix-induced decrease of (x43 in surface is not prevented by SB202190 or DTT. $\boldsymbol{a}$, Confocal representative pictures depicting $\mathrm{C} \times 43$ immunolabeling, made with a monoclonal $\mathrm{C} x 43$ antibody, in astrocyte cultures under untreated control condition $\left(\boldsymbol{a}_{\mathbf{1}}\right)$ or after treatment with Mix for $24 \mathrm{~h}\left(\boldsymbol{a}_{2}\right)$. Moreover, astrocytes were also cotreated either with Mix and SB202190 for $24 \mathrm{~h}\left(\boldsymbol{a}_{3}\right)$ or with Mix for $24 \mathrm{~h}$ and DTT, coapplied during the last $10 \mathrm{~min}\left(\boldsymbol{a}_{4}\right)$. Scale bar, $50 \mu \mathrm{m} . \boldsymbol{b}, \boldsymbol{c}$, Representative Western blot analysis of total $\mathrm{C} \times 43$ expression $(\boldsymbol{b})$ and cell surface biotinylated $\mathrm{Cx} 43$ (c) from astrocyte cultures under untreated control condition (lane c) or after $24 \mathrm{~h}$ exposure with Mix. SB202190 was coapplied with Mix for $24 \mathrm{~h}$ (lane SB), similar to DTT coapplied during the last 10 min of Mix treatment (lane DTT). In $\boldsymbol{b}$, a total of $20 \mu \mathrm{g}$ of protein was loaded per lane, and in c, the total amount of biotinylated protein was loaded in each lane. Western blots shown in $\boldsymbol{b}$ and $\boldsymbol{c}$ were developed for different periods of time and, thus, levels are not comparable. Similar observations were performed for both immunofluorescence and Western blot analysis in four independent experiments.

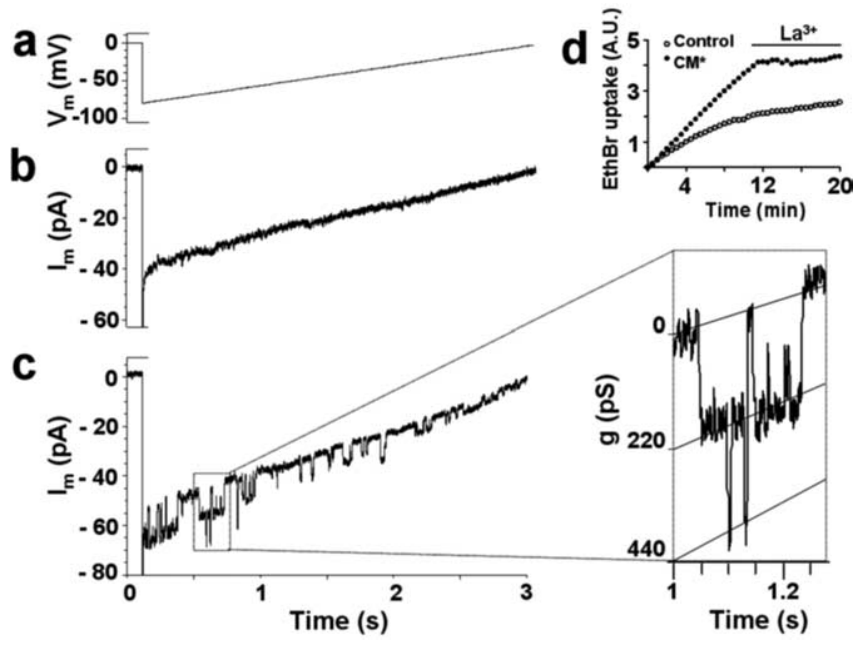

Figure 7. Conditioned medium harvested from activated microglia induces unitary current events of $\mathrm{Cx} 43$ hemichannels in cortical astrocytes. $\boldsymbol{a}$, Voltage ramps from -80 to 0 $\mathrm{mV}, 3 \mathrm{~s}$ in duration, were applied. The ramp was initiated by a transition from 0 to -80 $\mathrm{mV} . \boldsymbol{b}, \boldsymbol{c}$, Currents of control and $\mathrm{CM}^{*}$-treated astrocytes for $24 \mathrm{~h}$, respectively. $\boldsymbol{b}, \boldsymbol{d}$, Under control conditions, no hemichannel openings were observed, and EthBr uptake was low. $c$, $\boldsymbol{d}$, In astrocytes treated for $24 \mathrm{~h}$ with $\mathrm{CM}^{*}$, hemichannel openings were clearly observed, and this cell showed close to twice the amount of EthBr uptake compared with cells under control conditions. The boxed region in $\boldsymbol{d}$ is shown as conductance at the right bottom where two hemichannels of $\sim 220 \mathrm{pS}$ each show transitions between closed to open states. Tilted traced along both closed, one open, and both open indicate the progressive changes in voltage during the ramp application. $\boldsymbol{d}$, In $\mathrm{CM}^{*}$-treated astrocytes, the EthBr uptake fraction sensitive to $\mathrm{La}^{3+}(200 \mu \mathrm{m})$ was bigger than in control cells, indicating that more hemichannels were open in $\mathrm{CM}^{*}$-treated cells.

ings performed in astrocytes demonstrate that treatment with $\mathrm{CM}^{*}$ generates singlechannel activity characterized by a unitary conductance $(\sim 220 \mathrm{pS})$ already reported for $\mathrm{Cx} 43$ hemichannels (Contreras et al., 2003) and clearly different from Px hemichannels that are between 475 and 550 pS (Bao et al., 2004). Moreover, these findings make a link between recent reports showing that gap junction channels and hemichannels are oppositely regulated in cell lines transfected with $\mathrm{Cx} 43$ (De Vuyst et al., 2007) and that proinflammatory cytokines affect the activity of $\mathrm{Cx}$ hemichannels in astrocytes (Morita et al., 2007).

Moreover, it has been reported that metabolic inhibition induces membrane permeabilization because of an increase in levels of Cx43 hemichannels at the surface of astrocytes (Retamal et al., 2006) but at the same time reduces $\mathrm{Cx} 43$ GJC (Contreras et al., 2002; Retamal et al., 2006). Moreover, in C6 glioma cell line, FGF-2 and LPS induce membrane permeabilization mediated by Cx43 hemichannels but close gap junction channels (De Vuyst et al., 2007). Here, we demonstrate that, in the presence of external calcium, inflammatory conditions involving activated MG enhance astrocyte $\mathrm{Cx} 43$ hemichannel activity and reduce intercellular communication mediated by $\mathrm{Cx} 43$ gap junction channels.

Regulatory pathways of $\mathrm{Cx} 43$ channels in inflammatory conditions

We further investigated the signaling pathways involved in this opposite regulation. Thus, we demonstrated that $\mathrm{p} 38$ activation induced by Mix and $\mathrm{CM}^{*}$ treatment is directly involved in processes that oppositely regulate $\mathrm{Cx} 43$ hemichannels and gap junction channels functions. This observation is in agreement with previous reports showing the following: (1) cytokines such as TNF- $\alpha$ and IL- $1 \beta$ induce p38 activation (Winston et al., 1997; Boone et al., 1998; Pavlovic et al., 2000; Pype et al., 2001), (2) GJC is inhibited by IL-1 $\beta$ in astrocytes (Duffy et al., 2000), and (3) this inhibition is prevented by SB203580 treatment and p38/SAPK2 inhibitor (Zvalova et al., 2004). Moreover, p38 activation is directly related to an increase in NOS activity and NO production (Da Silva et al., 1997; Cheng et al., 2001) and the addition of DTT (a sulfhydryl reducing agent) to astrocytes treated with Mix and $\mathrm{CM}^{\star}$ induced rapid closure of $\mathrm{Cx} 43$ hemichannels. Because the Mix-induced membrane permeabilization occurred with a reduction in Cx43 hemichannel levels at the cell surface, it is likely that p38 through NO production induces $\mathrm{Cx} 43$ hemichannel opening. Moreover, NO donors induce opening of astrocytic $\mathrm{Cx} 43$ hemichannels, a response associated with $\mathrm{Cx} 43$ nitrosylation and rapidly reversed with DTT (Retamal et al., 2006). In contrast, DTT did not recover the dye coupling decrease induced by CM or Mix, suggesting that the action of p 38 over gap junction channels is different. Currently, we can discard the possibility of oxidations sensitive to DTT, such as nitrosylation, gluthathionylation, and dishylfyde bounds, but other oxidation such as tyrosine nitration remains possible. In addition, the reduction in 

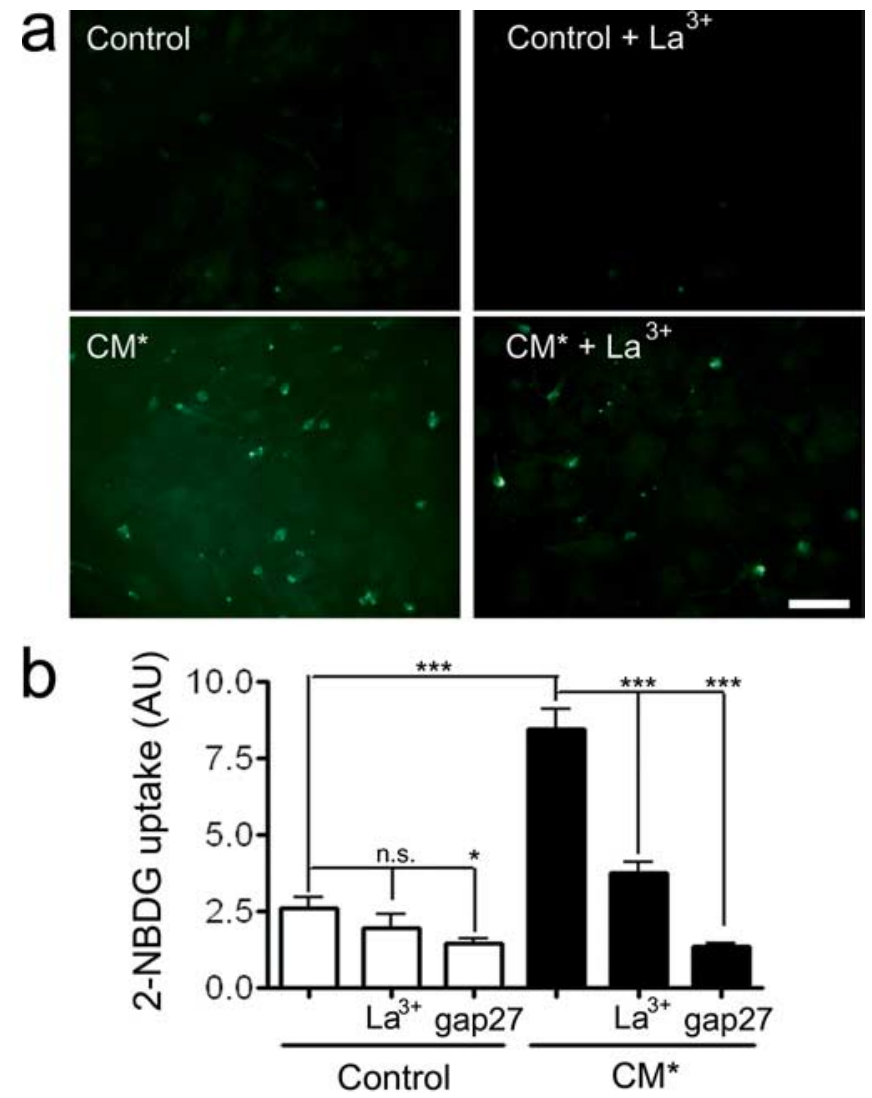

Figure 8. Proinflammatory treatment increases glucose uptake in astrocytes. $\boldsymbol{a}$, Confluent astrocyte cultures were treated with $\mathrm{CM}^{*}$ for $24 \mathrm{~h}$, and then uptake of 2-NBDG, a fluorescent glucose derivative, was determined at $488 \mathrm{~nm}$. $\boldsymbol{a}$, Snapshot pictures of fields showing nuclei staining of astrocytes treated as indicated for each panel. Scale bar, $100 \mu \mathrm{m}$. $\boldsymbol{b}$, Graph showing the uptake of 2-NBDG expressed as arbitrary fluorescent units in astrocytes under control conditions (Control) or treated for $24 \mathrm{~h}$ with MG conditioned medium (CM*). In some experiments, cells were treated with either $\mathrm{La}^{3+}(200 \mu \mathrm{m})$ or gap27 $(300 \mu \mathrm{g} / \mathrm{ml})$ for $10 \mathrm{~min}$ before dye uptake assay. Each plotted value represents the mean \pm SEM of four independent determinations. n.s., No significant difference; ${ }^{*} p<0.05$ and ${ }^{* * *} p<0.001$.

dye coupling cannot be attributed to a reduction in $\mathrm{Cx} 43$ levels or phosphorylation state detectable by changes in electrophoretic mobility, because in astrocytes treated with Mix in the presence of SB202190, the Cx43 total levels and pattern of immunoreactive bands were similar to cells treated only with Mix, but the cells became coupled. Moreover, in immunofluorescence labeling, we did not see obvious redistribution of $\mathrm{Cx} 43$ after the reduction in GJC that was attributable to a reduction in the amount or size of gap junction plaque. Thus, after treatment with Mix, in the presence of SB202190, no obvious subcellular redistribution of Cx43 was noted. In conclusion, we suggest that p38 affects Cx43 forming hemichannel activity through changes in their redox potential and possibly affects $\mathrm{Cx} 43$ forming gap junction channels through changes in their phosphorylation state unrelated to shifts in electrophoretic mobility or oxidation modifications of $\mathrm{Cx} 43$ insensitive to DTT, but this hypothesis needs to be studied (Cooper and Lampe, 2002; Ek-Vitorin et al., 2006).

\section{An alternative pathway for glucose entry in inflammatory astrocytes}

The opening of Cx43 hemichannels may represent a new metabolic pathway for glucose entry in astrocytes during pathological conditions. Indeed, this work identifies an alternative pathway that could contribute to the increase of glucose uptake reported in several uncoupling situations (Giaume et al., 1997; Tabernero et al., 2006) and that was correlated with the upregulation of GLUT-1 and type I hexokinase expression levels and to the induction of the expression of new isoforms, such as GLUT-3 and type II hexokinase (Sánchez-Alvarez et al., 2004). Because the permeability of the blood-brain barrier is increased during the inflammatory response (Schnell et al., 1999), more glucose coming from the circulation will be available in the brain. Thus, in addition to transporters, the entry of glucose through hemichannels could contribute to an increase of lactate formation in astrocytes that are adapted for anaerobic metabolism that would contribute to metabolic acidosis. The use of a fluorescent glucose compound demonstrates that proinflammatory compounds inhibit the intercellular diffusion of glucose while they favor its uptake. Until now, although dyes have been shown to be taken up through hemichannels in astrocytes, only a release of bioactive molecules has been described to occur through this pathway in astrocytes and other cell types. This is the case for ATP (Cotrina et al., 1998), $\mathrm{NAD}^{+}$(Bruzzone et al., 2001), glutamate (Ye et al., 2003), and glutathione (Rana and Dringen, 2007). Furthermore, the opposite regulation of $\mathrm{Cx}$ channels may lead to a failure in glucose trafficking and certainly will modify the metabolic status of astrocytes, a statement that should now be taken into account when considering the role of glia in brain inflammation.

\section{Pathological significance}

Although these results were obtained from cocultures of cortical glial cells and cannot be generalized to all brain structures, they provide a new insight into the field of research that attempts to understand the role of astrocytic connexins in neuronal survival. The activation of Cx43 hemichannels occurs in astrocytes cocultured with MG stimulated by low LPS doses and in the presence of extracellular $\mathrm{Ca}^{2+}$, whereas most observations of $\mathrm{Cx} 43$ hemichannel opening require the absence of this divalent cation (Sáez et al., 2005; Spray et al., 2006). This result indicates that the opening of hemichannels might occur in pathological situations that have already been correlated with an inhibition of GJC (Rouach et al., 2002a). Accordingly, this opposite regulation of $\mathrm{Cx} 43$ channel properties and its balance should now be taken into account for the interpretation of the role of astrocyte Cxs in brain pathologies in which an inflammatory response generally takes place. In the literature, the role of Cx-based channels is rather controversial and alternates between a protective and deleterious role to neuronal susceptibility to injuries (Perez et al., 2003; Rouach et al., 2002a; Nakase and Naus, 2004; Farahani et al., 2005). This controversy might be explained because, until now, only GJC was considered as the $\mathrm{Cx} 43$ channel function involved in neuroprotection. Consequently, because $\mathrm{Cx} 43$ gap junction channels and hemichannels are regulated oppositely during inflammatory treatments, it is clear now that both Cx43-based channels properties should be considered.

\section{References}

Badger AM, Cook MN, Lark MW, Newman-Tarr TM, Swift BA, Nelson AH, Barone FC, Kumar S (1998) SB 203580 inhibits p38 mitogen-activated protein kinase, nitric oxide production, and inducible nitric oxide synthase in bovine cartilage-derived chondrocytes. J Immunol 161:467-473.

Bao L, Locovei S, Dahl G (2004) Pannexin membrane channels are mechanosensitive conduits for ATP. FEBS Lett 572:65-68.

Battelino T, Goto M, Krzisnik C, Zeller WP (1999) Tumor necrosis factoralpha alters glucose metabolism in suckling rats. J Lab Clin Med 133:583-589.

Blomstrand F, Giaume C (2006) Kinetics of endothelin-induced inhibition and glucose permeability of astrocyte gap junctions. J Neurosci Res 83:996-1003. 
Boone E, Vandevoorde V, De Wilde G, Haegeman G (1998) Activation of p42/p44 mitogen-activated protein kinases (MAPK) and p38 MAPK by tumor necrosis factor (TNF) is mediated through the death domain of the 55-kDa TNF receptor. FEBS Lett 441:275-280.

Bruzzone R, Barbe MT, Jakob NJ, Monyer H (2005) Pharmacological properties of homomeric and heteromeric pannexin hemichannels expressed in Xenopus oocytes. J Neurochem 92:1033-1043.

Bruzzone S, Guida L, Zocchi E, Franco L, De Flora A (2001) Connexin 43 hemichannels mediate $\mathrm{Ca}^{2+}$-regulated transmembrane $\mathrm{NAD}^{+}$fluxes in intact cells. FASEB J 15:10-12.

Calvo CF, Cesselin F, Gelman M, Glowinski J (2000) Identification of an opioid peptide secreted by rat embryonic mixed brain cells as a promoter of macrophage migration. Eur J Neurosci 12:2676-2684.

Cheng A, Chan SL, Milhavet O, Wang S, Mattson MP (2001) p38 MAP kinase mediates nitric oxide-induced apoptosis of neural progenitor cells. J Biol Chem 276:43320-43327.

Cherian PP, Siller-Jackson AJ, Gu S, Wang X, Bonewald LF, Sprague E, Jiang JX (2005) Mechanical strain opens connexin 43 hemichannels in osteocytes: a novel mechanism for the release of prostaglandin. Mol Biol Cell 16:3100-3106.

Clerk A, Harrison JG, Long CS, Sugden PH (1999) Pro-inflammatory cytokines stimulate mitogen-activated protein kinase subfamilies, increase phosphorylation of c-Jun and ATF2 and upregulate c-Jun protein in neonatal rat ventricular myocytes. J Mol Cell Cardiol 31:2087-2099.

Contreras JE, Sánchez HA, Eugenín EA, Speidel D, Theis M, Willecke K, Bukauskas FF, Bennett MVL, Sáez JC (2002) Metabolic inhibition induces opening of unapposed connexin 43 gap junction hemichannels and reduces gap junctional communication in cortical astrocytes in culture. Proc Natl Acad Sci USA 99:495-500.

Contreras JE, Sáez JC, Bukauskas FF, Bennett MVL (2003) Gating and regulation of connexin 43 (Cx43) hemichannels. Proc Natl Acad Sci USA 100:11388-11393.

Cooper CD, Lampe PD (2002) Casein kinase 1 regulates connexin-43 gap junction assembly. J Biol Chem 277:44963-44968.

Cotrina ML, Kang J, Lin JH, Bueno E, Hansen TW, He L, Liu Y, Nedergaard M (1998) Astrocytic gap junctions remain open during ischemic conditions. J Neurosci 18:2520-2537.

Da Silva J, Pierrat B, Mary JL, Lesslauer W (1997) Blockade of p38 mitogenactivated protein kinase pathway inhibits inducible nitric-oxide synthase expression in mouse astrocytes. J Biol Chem 272:28373-28380.

Davalos D, Grutzendler J, Yang G, Kim JV, Zuo Y, Jung S, Littman DR, Dustin ML, Gan WB (2005) ATP mediates rapid microglial response to local brain injury in vivo. Nat Neurosci 8:752-758.

De Vuyst E, Decrock E, De Bock M, Yamasaki H, Naus CC, Evans WH, Leybaert L (2007) Connexin hemichannels and gap junction channels are differentially influenced by lipopolysaccharide and basic fibroblast growth factor. Mol Biol Cell 18:34-46.

Duffy HS, John GR, Lee SC, Brosnan CF, Spray DC (2000) Reciprocal regulation of the junctional proteins claudin-1 and connexin 43 by interleukin-1 $\beta$ in primary human fetal astrocytes. J Neurosci 20:RC114(1-6).

Ek-Vitorin JF, King TJ, Heyman NS, Lampe PD, Burt JM (2006) Selectivity of connexin 43 channels is regulated through protein kinase C-dependent phosphorylation. Circ Res 98:1498-1505.

Eugenín E, Eckardt D, Theis M, Willecke K, Bennett M, Sáez JC (2003) Microglia at stab wounds express connexin 43 and in vitro form gap junctions after treatment with interferon- $\gamma$ and tumor necrosis factor- $\alpha$. Proc Natl Acad Sci USA 98:4190-4195.

Evans WH, De Vuyst E, Leybaert L (2006) The gap junction cellular internet: connexin hemichannels enter the signalling limelight. Biochem J 397:1-14.

Farahani R, Pina-Benabou MH, Kyrozis A, Siddiq A, Barradas PC, Chiu FC, Cavalcante LA, Lai JC, Stanton PK, Rozental R (2005) Alterations in metabolism and gap junction expression may determine the role of astrocytes as "good samaritans" or executioners. Glia 50:351-361.

Faustmann P, Haase C, Romberg S, Hinkerohe D, Szlachta D, Smikalla D, Krause D, Dermietzel R (2003) Microglia activation influences dye coupling and Cx43 expression of the astrocytic network. Glia 42:101-108.

Fukunaga R, Hunter T (1997) MNK1, a new MAP kinase-activated protein kinase, isolated by a novel expression screening method for identifying protein kinase substrates. EMBO J 16:1921-1933.

Giaume C, Fromaget C, El Aoumari A, Cordier J, Glowinski J, Gros D (1991)
Gap junctions in cultured astrocytes: single-channel currents and characterization of channel-forming protein. Neuron 6:133-143.

Giaume C, Tabernero A, Medina JM (1997) Metabolic trafficking through astrocytic gap junctions. Glia 21:114-123.

Guan Z, Baier LD, Morrison AR (1997) p38 mitogen-activated protein kinase down-regulates nitric oxide and up-regulates prostaglandin E2 biosynthesis stimulated by interleukin-1beta. J Biol Chem 272:8083-8089.

Gutierrez-Venegas G, Maldonado-Frias S, Ontiveros-Granados A, KawasakiCardenas P (2005) Role of p38 in nitric oxide synthase and cyclooxygenase expression, and nitric oxide and PGE2 synthesis in human gingival fibroblasts stimulated with lipopolysaccharides. Life Sci 77:60-73.

Huang Y, Grinspan JB, Abrams CK, Scherer SS (2007) Pannexin1 is expressed by neurons and glia but does not form functional gap junctions. Glia 55:46-56.

John SA, Kondo R, Wang SY, Goldhaber JI, Weiss JN (1999) Connexin-43 hemichannels opened by metabolic inhibition. J Biol Chem 274:236-240.

Koulakoff A, Meme W, Calvo CF, Ezan P, Rouach N, Giaume C (2003) Neurons and brain macrophages regulate connexin expression in cultured astrocytes. Cell Commun Adhes 10:407-411.

Lai CP, Bechberger JF, Thompson RJ, MacVicar BA, Bruzzone R, Naus CC (2007) Tumor-suppressive effects of pannexin 1 in C6 glioma cells. Cancer Res 67:1545-1554.

Little AR, O'Callagha JP (2001) Astrogliosis in the adult and developing CNS: is there a role for proinflammatory cytokines? Neurotoxicology 22:607-618.

Même W, Calvo C, Froger N, Ezan P, Amigou E, Koulakoff A, Giaume C (2006) Proinflammatory cytokines released from microglia inhibit gap junctions in astrocytes: potentiation by $\beta$-amyloid. FASEB J 20:494-496.

Minami M, Katayama T, Satoh M (2006) Brain cytokines and chemokines: roles in ischemic injury and pain. J Pharmacol Sci 100:461-470.

Mitchell MD, Laird RE, Brown RD, Long CS (2007) IL-1beta stimulates rat cardiac fibroblast migration via MAP kinase pathways. Am J Physiol 292:H1139-H1147.

Morita M, Saruta C, Kozuka N, Okubo Y, Itakura M, Takahashi M, Kudo Y (2007) Dual regulation of astrocyte gap junction hemichannels by growth factors and a pro-inflammatory cytokine via the mitogenactivated protein kinase cascade. Glia 55:508-515.

Nakase T, Naus CC (2004) Gap junctions and neurological disorders of the central nervous system. Biochim Biophys Acta 1662:149-158.

Pavlovic D, Andersen NA, Mandrup-Poulsen T, Eizirik DL (2000) Activation of extracellular signal-regulated kinase (ERK)1/2 contributes to cytokine-induced apoptosis in purified rat pancreatic beta-cells. Eur Cytokine Netw 11:267-274.

Pelegrin P, Surprenant A (2006) Pannexin-1 mediates large pore formation and interleukin-1beta release by the ATP-gated P2X7 receptor. EMBO J 25:5071-5082.

Perez VJL, Frantseva MV, Naus CC (2003) Gap junctions and neuronal injury: protectants or excocutors? Neuroscientist 9:5-9.

Pype JL, Xu H, Schuermans M, Dupont LJ, Wuyts W, Mak JC, Barnes PJ, Demedts MG, Verleden GM (2001) Mechanisms of interleukin 1betainduced human airway smooth muscle hyporesponsiveness to histamine. Involvement of p38 MAPK NF-kappaB. Am J Respir Crit Care Med 163:1010-1017.

Porras OH, Loaiza A, Barros LF (2004) Glutamate mediates acute glucose transport inhibition in hippocampal neurons. J Neurosci 24:9669-9673.

Rana S, Dringen R (2007) Gap junction hemichannel-mediated release of glutathione from cultured rat astrocytes. Neurosci Lett 415:45-48.

Reaume AG, De Sousa PA, Kulkarni S, Langille BL, Zhu D, Davies TC, Juneja SC, Kidder GM, Rossant J (1995) Cardiac malformation in neonatal mice lacking connexin43. Science 267:1831-1834.

Retamal MA, Cortés CJ, Reuss L, Bennett MV, Sáez JC (2006) S-nitrosylation and permeation through connexin 43 hemichannels in astrocytes: induction by oxidant stress and reversal by reducing agents. Proc Natl Acad Sci USA 103:4475-4480.

Retamal MA, Schalper KA, Shoji KF, Bukauskas FF, Bennett MVL, Sáez JC (2007) Opening of connexin 43 hemichannels is increased by lowering intracellular redox potential. Proc Natl Acad Sci USA 104:8322-8327.

Robinson KA, Stewart CA, Pye QN, Nguyen X, Kenney L, Salzman S, Floyd RA, Hensley K (1999) Redox-sensitive protein phosphatase activity regulates the phosphorylation state of $\mathrm{p} 38$ protein kinase in primary astrocyte culture. J Neurosci Res 55:724-732.

Rossa C, Ehmann K, Liu M, Patil C, Kirkwood KL (2006) MKK3/6-p38 
MAPK signaling is required for IL-1beta and TNF-alpha-induced RANKL expression in bone marrow stromal cells. J Int Cyt Res 26:719-729.

Rouach N, Avignone E, Même W, Koulakoff A, Venance L, Blomstrand F, Giaume C (2002a) Gap junctions and connexin expression in the normal and pathological central nervous system. Biol Cell 94:457-475.

Rouach N, Calvo C, Glowinski J, Giaume C (2002b) Brain macrophages inhibit gap junctional communication and downregulate connexin 43 expression in cultured astrocyte. Eur J Neurosci 15:403-407.

Sáez JC, Retamal MA, Basilio D, Bukauskas FF, Bennett MV (2005) Connexin-based gap junction hemichannels: gating mechanisms. Biochim Biophys Acta 1711:215-224.

Sánchez-Alvarez R, Tabernero A, Medina JM (2004) Endothelin-1 stimulates the translocation and upregulation of both glucose transporter and hexokinase in astrocytes: relationship with gap junctional communication. J Neurochem 89:703-714.

Schnell L, Fearn S, Schwab ME, Perry VH, Anthony DC (1999) Cytokineinduced acute inflammation in the brain and spinal cord. J Neuropathol Exp Neurol 58:245-254.

Sofroniew MV (2005) Reactive astrocytes in neural repair and protection. Neuroscientist 11:400-407.

Spray DC, YeZC, Ransom BR (2006) Functional connexin "hemichannels": a critical appraisal. Glia 54:758-773.

Stout CE, Costantin JL, Naus CC, Charles AC (2002) Intercellular calcium signaling in astrocytes via ATP release through connexin hemichannels. J Biol Chem 277:10482-10488.

Tabernero A, Medina JM, Giaume C (2006) Glucose metabolism and pro- liferation in glia: role of astrocytic gap junctions. J Neurochem 99:1049-1061.

Theriault E, Frankenstein UN, Hertzberg EL, Nagy JI (1997) Connexin43 and astrocytic gap junctions in the rat spinal cord after acute compression injury. J Comp Neurol 382:199-214

Vergara L, Bao X, Bello-Reuss E, Reuss L (2003) Do connexin 43 gapjunctional hemichannels activate and cause cell damage during ATP depletion of renal-tubule cells? Acta Physiol Scand 179:33-38.

Winston BW, Chan ED, Johnson GL, Riches DW (1997) Activation of p38mapk, MKK3, and MKK4 by TNF-alpha in mouse bone marrowderived macrophages. J Immunol 159:4491-4497.

Xu Z, Wang BR, Wang X, Kuang F, Duan XL, Jiao XY, Ju G (2006) ERK1/2 and p38 mitogen-activated protein kinase mediate iNOS-induced spinal neuron degeneration after acute traumatic spinal cord injury. Life Sci 79:1895-1905.

Ye ZC, Wyeth MS, Baltan-Tekkok S, Ransom BR (2003) Functional hemichannels in astrocytes: a novel mechanism of glutamate release. J Neurosci 23:3588-3596.

Yu N, Maciejewski-Lenoir D, Bloom FE, Magistretti PS (1995) Tumor necrosis factor-alpha and interleukin-1 alpha enhance glucose utilization by astrocytes: involvement of phospholipase A2. Mol Pharmacol 48:550-558.

Zhang J, Wang S, Kern S, Cui X, Danner RL (2007) Nitric oxide downregulates polo-like kinase 1 through a proximal promoter cell cycle gene homology region. J Biol Chem 282:1003-1009.

Zvalova D, Codier J, Mesnil M, Junier MP, Chneiweiss H (2004) p38/ SAPK2 controls gap junction closure in astrocytes. Glia 46:323-333. 